MARCELO SUCCI DE JESUS FERREIRA

\title{
UMA ARQUITETURA DE SISTEMAS DISTRIBUÍDOS PARA WEBLABS DE SERVIÇOS AMBIENTAIS
}

Dissertação apresentada à Escola Politécnica da Universidade de São Paulo para obtenção do título de Mestre em Engenharia. 
MARCELO SUCCI DE JESUS FERREIRA

\section{UMA ARQUITETURA DE SISTEMAS DISTRIBUÍDOS PARA WEBLABS DE SERVIÇOS AMBIENTAIS}

Dissertação apresentada à Escola Politécnica da Universidade de São Paulo para obtenção do título de Mestre em Engenharia.

Área de Concentração:

Sistemas Digitais

Orientador:

Prof. Dr. Pedro Luiz Pizzigatti Corrêa 
Este exemplar for revisado e alterado em relação à versão original, sob responsabilidade única do autor e com anuência de seu orientador.

São Paulo, julho de 2007

Assinatura do Autor

Assinatura do Orientador

\section{FICHA CATALOGRÁFICA}

Ferreira, Marcelo Succi de Jesus

Uma arquitetura de sistemas distribuídos para weblabs de serviços ambientais/ M.S. de J.Ferreira. - ed.rev. -São Paulo, 2007.

$83 \mathrm{p}$.

Dissertação (Mestrado) - Escola Politécnica da Universidade de São Paulo. Departamento de Engenharia de Computação e Sistemas Digitais.

1.Sistemas de informação 2.Banco de dados distribuídos 3.Ecossistemas (Serviços) I.Universidade de São Paulo. Escola Politécnica. Departamento de Engenharia de Computação e Sistemas Digitais II.t. 
A minha esposa Maria Luiza e aos meus pais, Roberto (em memória) e Maria Helena, pelo apoio incondicional e ao meus filhos Pedro Henrique e Rafael pelos muitos momentos de alegria. 


\section{AGRADECIMENTOS}

Ao meu orientador, Prof. Pedro Luiz Pizzigatti Corrêa, pelas valiosas orientações, incentivo e confiança depositada ao longo deste trabalho.

À minha esposa Maria Luiza, pelo amor, apoio, compreensão e renúncias durante esta tarefa.

Ao Professores Antônio Mauro Saraiva e Líria Matsumoto Sato, pela contribuição durante a fase de qualificação. Ao Prof. Saraiva também pelos incentivos durante esta convivência.

Aos engenheirandos Rafael Hideo Kawakami e Leonardo Bessa pelas várias contribuições no decorrer da modelagem e implementação da arquitetura proposta .

Aos administradores da rede do Instituto de Matemática e Estatística da USP Airton Vilela, Selma Kurebayashi e Gledsley Muller, pelo inestimável apoio profissional.

À Fundação de Amparo à Pesquisa do Estado de São Paulo (FAPESP) pelo custeio do Projeto ViNCES, processo no. 03/08134-4.

A todos aqueles que direta ou indiretamente contribuíram para este trabalho, meus sinceros agradecimentos. 
"Nós não herdamos a Terra de nossos ancestrais, nós a emprestamos de nossas crianças" Atribuído ao Chefe Indígena Norte-Americano Seattle 


\section{RESUMO}

Serviços Ambientais - purificação do ar, estabilização do clima, polinização de culturas, etc. - são funções fundamentais na sustentação da vida humana e têm sua importância econômica cada vez mais evidenciada. Para melhor estudar estes Serviços e saber como eles se comportam, são necessárias novas abordagens para disponibilizar, integrar e compartilhar os dados existentes sobre eles. O projeto ViNCES (Virtual Network Center of Ecosystem Services) propõe a utilização de laboratórios acessíveis via internet - weblabs - com foco em Serviços Ambientais a fim de promover uma melhor compreensão destes serviços. Assim, com o objetivo de viabilizar esta proposta, desenvolveu-se uma arquitetura que permite o acesso aos diversos weblabs do projeto de maneira integrada, disponibilizando os dados de experimentos realizados a um maior número de pesquisadores. A arquitetura proposta fundamenta-se no paradigma de Arquitetura Orientada a Serviços e atende a requisitos de acesso centralizado aos weblabs para a realização e recuperação de experimentos de maneira remota. Esta arquitetura aproveita outras pesquisas na área de Ecoinformática, considerando soluções já existentes no projeto SEEK (Science Environment for Ecological Knowledge). Desta maneira, adota o padrão de metadados EML (Ecological Metadata Language) para a transferência e armazenamento de dados dos experimentos, permitindo que os experimentos fiquem disponíveis a outros pesquisadores que utilizem a infra-estrutura do projeto SEEK.

PALAVRAS-CHAVE : weblabs, serviços ambientais, SEEK, arquitetura distribuída. 


\begin{abstract}
Ecosystem Services - air purification, climate estabilization, crop pollination, etc. - are essential to sustain human life.Their economic importance is becoming more and more recognized. In order to better study these Services and learn about their behaviour, new approaches are needed for making available, integrating and sharing existing data about them. The ViNCES (Virtual Network Center of Ecosystem Services) project proposes the use of remotely accessible laboratories - weblabs - focused on Ecosystem Services to better understanding these services. In this way, an architecture was developed that allows access to project's weblabs in an integrated way, giving access to collected data for more researchers. The proposed architecture is based on the SOA (Service Oriented Architecture) paradigm and considers requirements of centralized access to laboratories to, in a remote way, make experiments and retrieve gathered data. This architecture considers other related initiatives in the ecoinformatics field, and uses solutions present in the SEEK (Science Environment for Ecological Knowledge) project. In this way, the EML (Ecological Metadata Language) standard was adopted for transporting and storaging experiments data, and allows that these data are available for other researchers that use the SEEK infra-structure.
\end{abstract}

KEYWORDS : weblabs, ecosystem services, SEEK, distributed architecture. 


\section{SUMÁRIO}

\section{LISTA DE FIGURAS \\ LISTA DE TABELAS \\ LISTA DE ABREVIATURAS E SIGLAS}

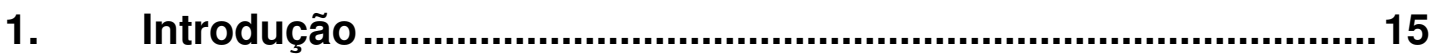

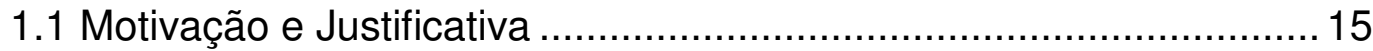

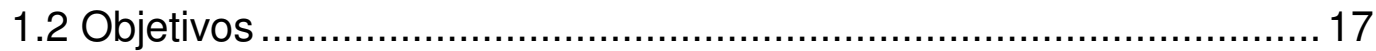

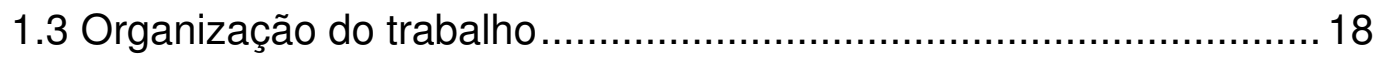

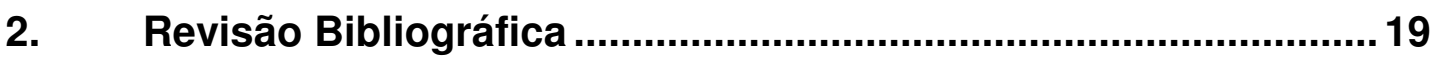

2.1 Sistemas de Informações Ecológicas ............................................... 19

2.1.1 Arquitetura de Sistemas Aplicada no Projeto SEEK …..................20

2.2 Componentes de software e serviços ............................................ 22

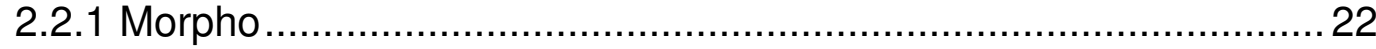

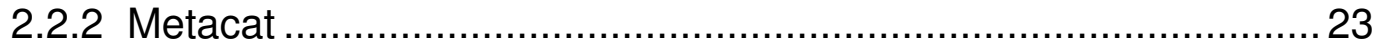

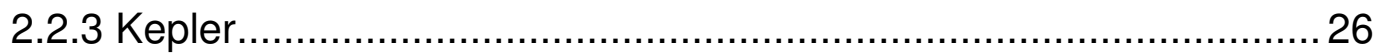

2.4 Padrões de metadados de biodiversidade ..................................... 29

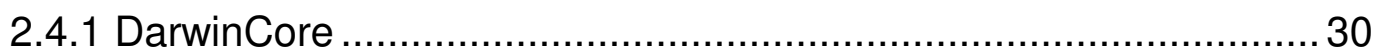

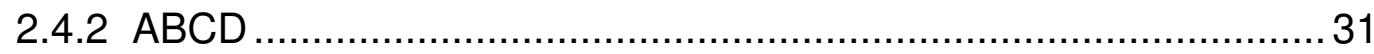

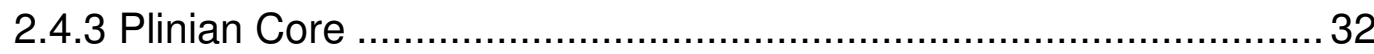

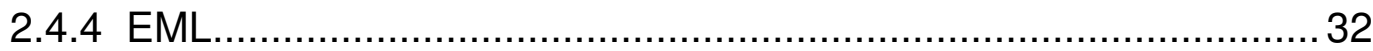

2.4.5 Comparação entre os padrões estudados …………………........ 34

2.4.6 Protocolos DiGIR, BioCASE e TAPIR ............................................ 36

2.5 Arquitetura Orientada a Serviços e Web Services ............................ 36

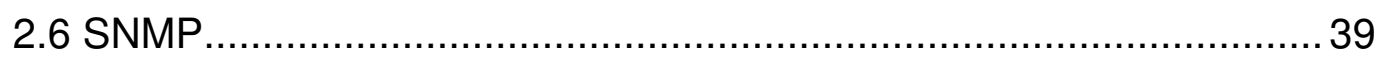

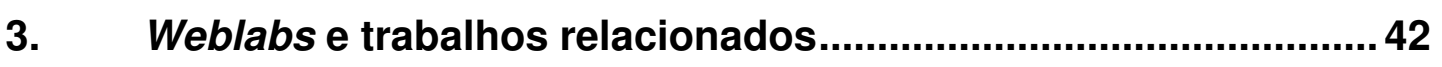

3.1 Laboratórios Reais $x$ Virtuais $x$ Remotos ......................................... 42

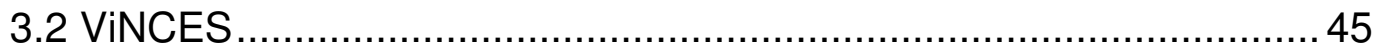

3.2.1 Laboratório de Abelhas ........................................................... 46

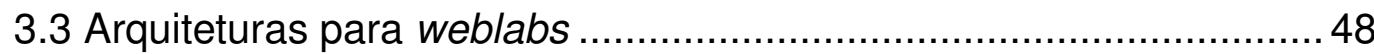

4. Arquitetura Geral do Sistema ..................................................... 51

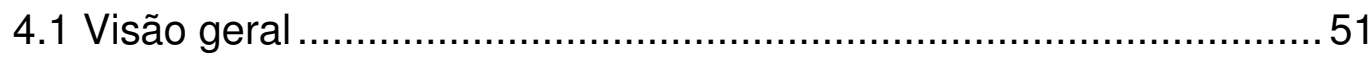




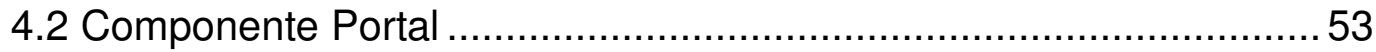

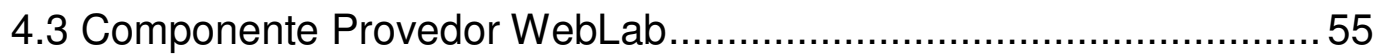

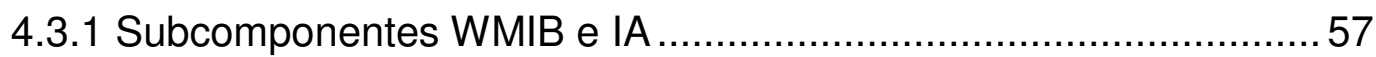

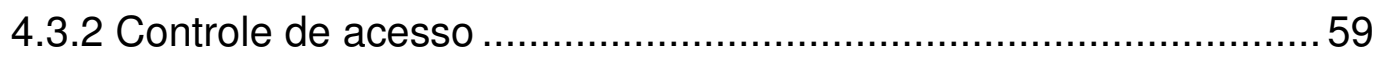

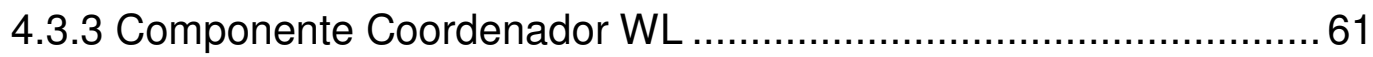

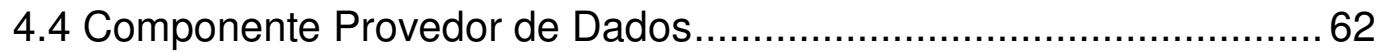

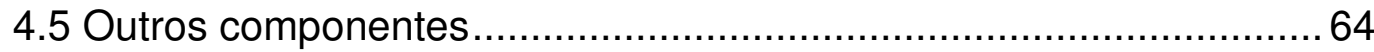

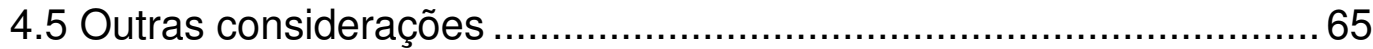

5. Estudo de caso - Laboratório de abelhas......................................66

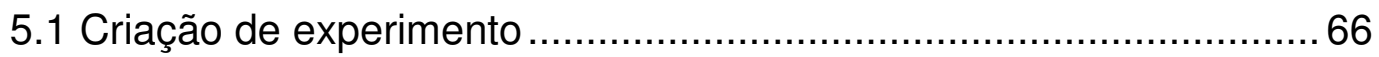

5.2 Recuperação de dados de experimento ………............................. 70

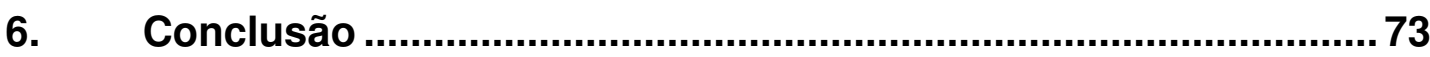

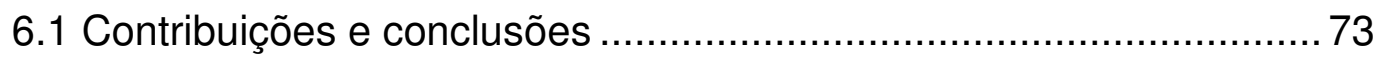

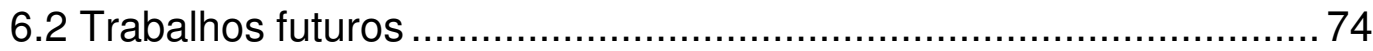




\section{LISTA DE FIGURAS}

Figura 2.1. Arquitetura utilizada no projeto SEEK, retirada de (PARTNERSHIP FOR BIODIVERSITY INFORMATICS, 2004).

Figura 2.2. Tela de pesquisa geográfica do MORPHO. .24

Figura 2.3. Integração Morpho e Metacat . Extraído de (HIGGINS; BERKLEY; JONES, 2002).

Figura 2.4. Exemplo de tela de desenho da seqüência de processos da aplicação Kepler para geração de dados no estudo de ocorrência de espécies utilizando o GARP (Genetic Algorithm for Rule Processing - Algoritmo Genético para Processamento de Regras). Extraído de (KEPLER; 2006). 27

Figura 2.5. Sistema Webbee - Diagrama Entidade-Relacionamento Simplificado do banco de dados. Extraído de (SARAIVA et al., 2003).

Figura 2.6. Sistema Webbee - Ficha da espécie Melípona quinquefasciata Lepeletier (mandaçaia da terra).

Figura 2.7. Estrutura de um pacote EML com a representação dos principais módulos.

Figura 2.8. Fragmento de um documento EML

Figura 2.9. Diagrama representativo da arquitetura de Web Services. 38

Figura 2.10. Principais elementos da Arquitetura SNMP

Figura 3.1 Diagrama representativo dos equipamentos utilizados no laboratório de abelhas. Extraído de (GIANNINI et al-a, 2006).

Figura 3.2. Montagem da câmera de vídeo e do microfone no laboratório de abelhas do projeto ViNCES. Extraído de (Giannini et al-b, 2006).

Figura 4.1. Arquitetura proposta para os WebLabs do projeto ViNCES. .52 
Figura 4.2 - Componente portal.

Figura 4.3. Componente Provedor WebLab.

.55

Figura 4.4. Exemplo de dados obtidos ao final do experimento em um um weblab do projeto ViNCES

Figura 4.5. Exemplo de interação para atuação em um instrumento. .58

Figura 4.6. Componente Provedor de Banco de Dados. .63

Figura 5.1. Apresentação dos WebLabs do Portal ViNCES. .67

Figura 5.2. Tela para criação de novo experimento. 67

Figura 5.3. Dados gerais do Experimento .68

Figura 5.4. Seleção de variáveis monitoradas. 69

Figura 5.5. Configuração da temperatura interna da colônia. 69

Figura 5.6. Agendamento do experimento no Weblab de abelhas. .70

Figura 5.7. Lista de experimentos do pesquisador. .71

Figura 5.8. Pesquisa genérica de experimentos disponíveis. .71

Figura 5.9. Dados de um experimento recuperado. .72 


\section{LISTA DE TABELAS}

Tabela 3.1. Comparação entre diversas classes de laboratórios. Extraído de (NEDIC;MACHOTKA;NAFALSKI, 2003). ................................................. 44

Tabela 4.1. Exemplo de extrato de um WMIB (Weblab MIB)..............................58 


\title{
LISTA DE ABREVIATURAS e SIGLAS
}

\author{
ACL Access Control List \\ DiGIR Distributed Generic Information Retrieval \\ DTD Document Type Definition \\ DwC Darwin Core \\ EML Ecological Metadata Language \\ FTP File Transfer Protocol \\ HTTP Hyper Text Transfer Protocol \\ IA Instrument Adapter \\ IABIN Inter-American Biodiversity Information Network \\ INBIO Insituto Nacional de Biodiversidad \\ KNB Knowledge Network for Biocomplexity \\ LDAP Lightweight Directory Access Protocol \\ LON Local Operating Network \\ MIB Management Information Base \\ NCEAS National Center for Ecological Analysis and Synthesis \\ REyE Red de Especies y Especímenes \\ SEEK Science Environment for Ecological Knowledge \\ SGBD Sistema Gerenciador de Banco de Dados \\ SMTP Simple MailTransfer Protocol \\ SNMP Simple Network Management Protocol \\ SOA Service Orientede Architecture \\ SOAP Simple Object Access Protocol \\ SQL $\quad$ Structured Query Language \\ TIDIA Tecnologia da Informação para o Desenvolvimento da Internet Avançada \\ TDWG Taxonomic Database Working Group \\ URI Universal Resource Identifier \\ ViNCES Virtual Network Center of Ecosystem Services \\ WMIB Weblab Management Information Base \\ WSDL Web Services Description Language \\ XML Extensible Markup Language
}




\section{Introdução}

\subsection{Motivação e Justificativa}

Ecosystem Services - traduzido como Serviços de Ecossistemas ou Serviços Ambientais - podem ser definidos como "uma larga faixa de condições e processos por meio dos quais ecossistemas naturais e as espécies que são parte dele ajudam a sustentar e manter a vida humana" (DAILY et al., 1997). Dentre os exemplos de Serviços Ambientais pode-se destacar a purificação do ar e da água, a geração e a renovação do solo e sua fertilidade, a polinização de culturas e o auxílio na estabilização do clima (DAILY et al., 1997). Sua importância econômica torna-se cada vez mais evidente. Em uma estimativa conservadora, Costanza et al. (1998) avaliaram os serviços ambientais de toda biosfera ao redor de US\$33 trilhões/ano em valores de 1998, quase o dobro da soma global dos Produtos Internos Brutos na época.

Um tema discutido atualmente no meio acadêmico envolvido com os Serviços Ambientais diz respeito à forma de disponibilizar os dados gerados e à integração das informações obtidas. Para abordar essa questão, está em andamento na Escola Politécnica da Universidade de São Paulo o projeto ViNCES (Virtual Network Center of Ecosystem Services) (TIDIA, 2005), que possibilitará o desenvolvimento e a utilização de padrões de interoperabilidade e de ferramentas computacionais que atendam a demanda de gerenciamento de informações com experimentos relacionados a serviços ambientais.

Estão envolvidos no projeto ViNCES um consórcio de laboratórios de pesquisa com foco em serviços ambientais, coordenado pelo Laboratório de Automação Agrícola do Departamento de Engenharia de Computação e Sistemas Digitais da Escola Politécnica da Universidade de São Paulo. Este projeto faz parte do programa TIDIA-Kyatera da Fundação de Amparo à Pesquisa do Estado de São Paulo - FAPESP (TIDIA, 2005), o qual visa à criação de uma rede de alta velocidade entre diversas instituições acadêmicas com o objetivo de permitir o desenvolvimento e a demonstração de tecnologias para aplicações de Internet Avançada.

Algumas pesquisas em serviços ambientais tratadas atualmente pelo ViNCES envolvem trabalhos nas áreas de fotossíntese e polinização. Através deste projeto, 
os Laboratórios participantes desse consórcio estarão disponíveis para a realização de experimentos remotamente via Internet, os quais são denominados weblabs (GARCIA-ZUBIA; DEL MORAL, 2005).

Além de weblabs, uma alternativa a realização de um experimento em um laboratório real é a utilização de simuladores. Desta forma, experiências podem ser conduzidas sem a necessidade de equipamentos físicos, tornando-se assim uma alternativa interessante quando analisada sob os aspectos de custo e escalabilidade.

Porém, o uso de simuladores é restrito a situações onde o experimento a ser simulado pode ser modelado matematicamente a priori. Tal fato restringe a aplicação desta alternativa em experimentos mais complexos, por exemplo, envolvendo organismos vivos.

Uma opção neste caso é a utilização de laboratórios acessíveis remotamente, os weblabs, nos quais os equipamentos do laboratório são conectados a uma rede no caso mais genérico, a Internet - para coleta de dados e alteração das condições do experimento. Desta maneira, tanto o acesso a dados, por exemplo, variáveis, sons, imagens, etc., quanto o controle dos equipamentos utilizados nos laboratórios podem ser feitos de maneira remota, através de uma rede de computadores.

Garcia-Zubia e Del Moral (2005) listam algumas vantagens relacionadas ao uso de weblabs, dentre elas:

- melhor uso da infra-estrutura do laboratório (disponível o tempo todo, dado que o weblab esteja operacional);

- melhor organização do tempo para a realização dos trabalhos;

- possibilidade de cursos à distância utilizando a infra-estrutura montada.

No entanto, algumas atividades em laboratório não são totalmente adequadas para a utilização em weblabs. Este é o caso do uso de práticas para formação de profissionais, nos quais as atividades presenciais têm melhor resultado, conforme estudo qualitativo mostrado em SOYSAL (2000).

Ainda assim, o uso de weblabs apresenta-se como uma solução interessante em termos de custo, flexibilidade de utilização e complexidade dos experimentos realizados. O mesmo trabalho mostra que experimentos integrados a computador (CIE-Computer Integrated Experiments) utilizados à distância têm melhor rendimento 
quando associados às atividades de coleta de dados, processamento numérico destes dados e posterior análise (SOYSAL, 2000). Estas atividades estão de acordo com 0 que se espera para o projeto ViNCES.

Para viabilizar a rede virtual de laboratórios através de weblabs, proposto no projeto ViNCES, é necessário o acesso de uma maneira uniforme aos serviços de cada laboratório da rede ViNCES. Considerada desta forma, a Arquitetura de Sistemas Orientada a Serviços (PAPAZOGLOU; GEORGAKOPOULOS, 2003) tornase uma alternativa interessante para abordar esse sistema, uma vez que define um modelo para integração entre portais e provedores de serviços. Porém, este modelo não é suficiente para definir uma plataforma interoperável entre os weblabs, já que cada provedor poderia fornecer serviços e dados com sintaxes e semânticas distintos, considerando os mais diversos tipos de serviços ambientais, o que inviabilizaria uma arquitetura aberta para integração de sistemas, descaracterizando, assim, a rede virtual de laboratórios ambientais do projeto VINCES.

Uma iniciativa que se destaca no gerenciamento de dados ambientais é a relacionada ao projeto SEEK (Science Environment for Ecological Knowledge) o qual tem por objetivo integrar dados ecológicos e permitir sua análise através do uso de serviços computacionais distribuídos (PARTNERSHIP FOR BIODIVERSITY INFORMATICS, 2004).

A arquitetura do SEEK é baseada em camadas, e prevê o uso de ferramentas para padronização de dados e de análises. O uso desta arquitetura é considerado promissor, porém vários aspectos de sua utilização ainda não foram avaliados, em especial sua aplicação voltada para weblabs.

\subsection{Objetivos}

O objetivo geral deste trabalho é a especificação de uma arquitetura de sistemas distribuídos segundo o paradigma de Arquitetura Orientada a Serviços para o compartilhamento de dados de weblabs.

Os objetivos específicos do trabalho são :

- identificar e especificar os serviços e as características gerais de um portal de weblabs para o projeto ViNCES, considerando os weblabs de abelhas e fotossíntese; 
- identificar um padrão para representar os dados e serviços que serão disponibilizados pelos weblabs;

- avaliar a arquitetura utilizada no projeto SEEK quanto à adequação para uso no compartilhamento de dados de weblabs de serviços ambientais;

- definir a arquitetura sob o paradigma de orientação a serviços (PAPAZOGLOU; GEORGAKOPOULOS, 2003);

- implementar um estudo de caso da arquitetura proposta, voltada para o weblab de abelhas.

\subsection{Organização do trabalho}

A organização do restante deste trabalho é descrita a seguir.

No capítulo 2 são estudados os conceitos relacionados aos temas de Ecoinformática, com ênfase no projeto SEEK e de padrões de metadados de biodiversidade. Também é feita uma contextualização do projeto WebBEE (SARAIVA, 2003). Por fim, uma revisão de conceitos de Arquitetura Orientada a Serviços e Web Services (W3C, 2002) é apresentada.

No capítulo 3 são abordados outros trabalhos relacionados às arquiteturas para o uso em weblabs, com uma revisão dos elementos dessas arquiteturas de interesse para essa pesquisa.

No capítulo 4 é apresentada a arquitetura proposta para compartilhamento de dados entre weblabs, com discussão em termos gerais de seus componentes e serviços.

No capítulo 5 é detalhada a arquitetura, mostrando os cenários de sua utilização para o Laboratório de Abelhas do projeto ViNCES, a qual será utilizada como um estudo de caso.

No capítulo 6 são apresentadas as análises e conclusões dos resultados obtidos. 


\section{Revisão Bibliográfica}

Este capítulo faz uma revisão sobre as iniciativas na área de Bioinformática e ferramentas de software que são relevantes para este trabalho. São apresentados também os principais padrões de metadados utilizados para compartilhamento de dados entre sistemas de informação para a biodiversidade.

Do ponto de vista computacional, são apresentados os conceitos de SOA (Service Oriented Architecture -Arquitetura Orientada a Serviços), utilizados na especificação da arquitetura proposta, além das principais tecnologias empregadas na arquitetura como Web Services e o paradigma da arquitetura SNMP (Simple Network Management Protocol - Protocolo Simples de Gerenciamento de Redes) (CASE et al., 1990).

\subsection{Sistemas de Informações Ecológicas}

A Bioinformática é uma das áreas de pesquisa em Computação de grande relevância atualmente. Em particular, a integração da Biologia, Ciência da Computação e Tecnologia da Informação para a pesquisa de temas ambientais, ecológicos e de biodiversidade, no que é conhecido como Ecoinformática (THE ECOINFORMATICS LABORATORY, 2006).

Dados ecológicos e de biodiversidade são heterogêneos, tornando o acesso, a integração e a análise destes dados uma tarefa não trivial. A variação semântica destes dados, devido a sua complexidade e diversidade de aplicações, coloca limitações no processo de pesquisa ecológica. Um exemplo, citado por Partnership for Biodiversity Informatics (2004), relata as dificuldades que teria um pesquisador interessado em estudar a forma como uma espécie intrusa iria se espalhar em uma determinada região. Mesmo que tivesse dados na literatura sobre a distribuição dos espécimes ocorrida em outras regiões, ele deveria tentar encontrar dados em outras bases de dados, em um processo penoso e às vezes frustrante. Ainda que conseguisse acesso a estes dados, novas dificuldades poderiam advir do tamanho da base de dados - faz-se o download da base toda ou apenas dos registros 
desejados ? - do formato dos dados - valores em branco indicam "não medidos" ou "não existentes" ? - e até mesmo de unidades utilizadas (Sistema Métrico x Sistema Britânico, por exemplo). Finalmente, os dados descobertos e tratados deveriam passar por análises em softwares matemáticos/estatísticos, os quais se apresentam hoje em grande variedade. Se outro pesquisador quiser fazer uma comparação de dados ou uma análise estendida, deveria geralmente dispor da mesma ferramenta computacional que o autor original, sob pena de restrições para a execução desta tarefa ou até mesmo de perda de capacidade de análise.

Para abordar essas questões, dentre as iniciativas na área de pesquisa em Ecoinformática, destaca-se o projeto SEEK (Science Environment for Ecological Knowledge - Ambiente de Ciência para o Conhecimento Ecológico), o qual tem por objetivo criar um arcabouço (framework) de tecnologia de informação com a meta de facilitar a localização e a integração de dados ecológicos e de biodiversidade, permitindo sua análise através do uso de serviços computacionais distribuídos (PARTNERSHIP FOR BIODIVERSITY INFORMATICS, 2004).

O projeto SEEK é financiado pela NSF (National Science Foundation - EUA), com final previsto para o ano de 2007, liderado por um consórcio de instituições situadas nos Estados Unidos: a University of Kansas, a University of New Mexico e o National Center for Ecological Analysis and Synthesis (NCEAS) da University of California em Santa Bárbara (EUA).

\subsubsection{Arquitetura de Sistemas Aplicada no Projeto SEEK}

A arquitetura de sistemas do projeto SEEK consiste de três camadas de softwares (ver Figura 2.1), sendo que cada uma delas aborda um dos aspectos dos problemas citados no item anterior. As camadas do projeto SEEK são apresentadas a seguir:

a) Camada de Acesso à Informação (Information Access Layer): tem por objetivo construir uma infra-estrutura para a descoberta e acesso de dados e dos serviços ecológicos distribuídos em diferentes servidores na rede Internet. Essa infra-estrutura oferece uma interface uniforme de serviços que podem ser acessados 
pela camada superior. Nessa arquitetura, este conjunto de serviços implementados em cada um dos servidores é denominado Ecogrid.

b) Camada de Mediação Semântica (Semantic Mediation Layer): tem a finalidade de permitir uma visão integrada sobre conjuntos de dados ecológicos e de biodiversidade a partir de fontes atualmente incompatíveis. Esta camada faz a mediação entre diferenças conceituais das diversas fontes de dados disponibilizadas pelo Ecogrid. Assim, dados provenientes de fontes diversas podem ser disponibilizados e agrupados, facilitando a construção de modelos e posterior análise. Tecnologias de Web Services são utilizadas nesta camada para permitir tal acesso uniforme.

c) Camada de Análise e Modelagem (Analysis and Modeling Layer): tem como função fornecer ferramentas para análise de biodiversidade e modelagem ecológica (PARTNERSHIP FOR BIODIVERSITY INFORMATICS, 2004). Nesta camada, a ferramenta Kepler (descrita na seção 2.1.2.3) apóia a análise e a modelagem de dados através de uma interface amigável, permitindo ao pesquisador concentrar-se na análise do experimento e não no funcionamento e peculiaridades da ferramenta utilizada.

\section{Science Environment for Ecological Knoledge (SEEK)}

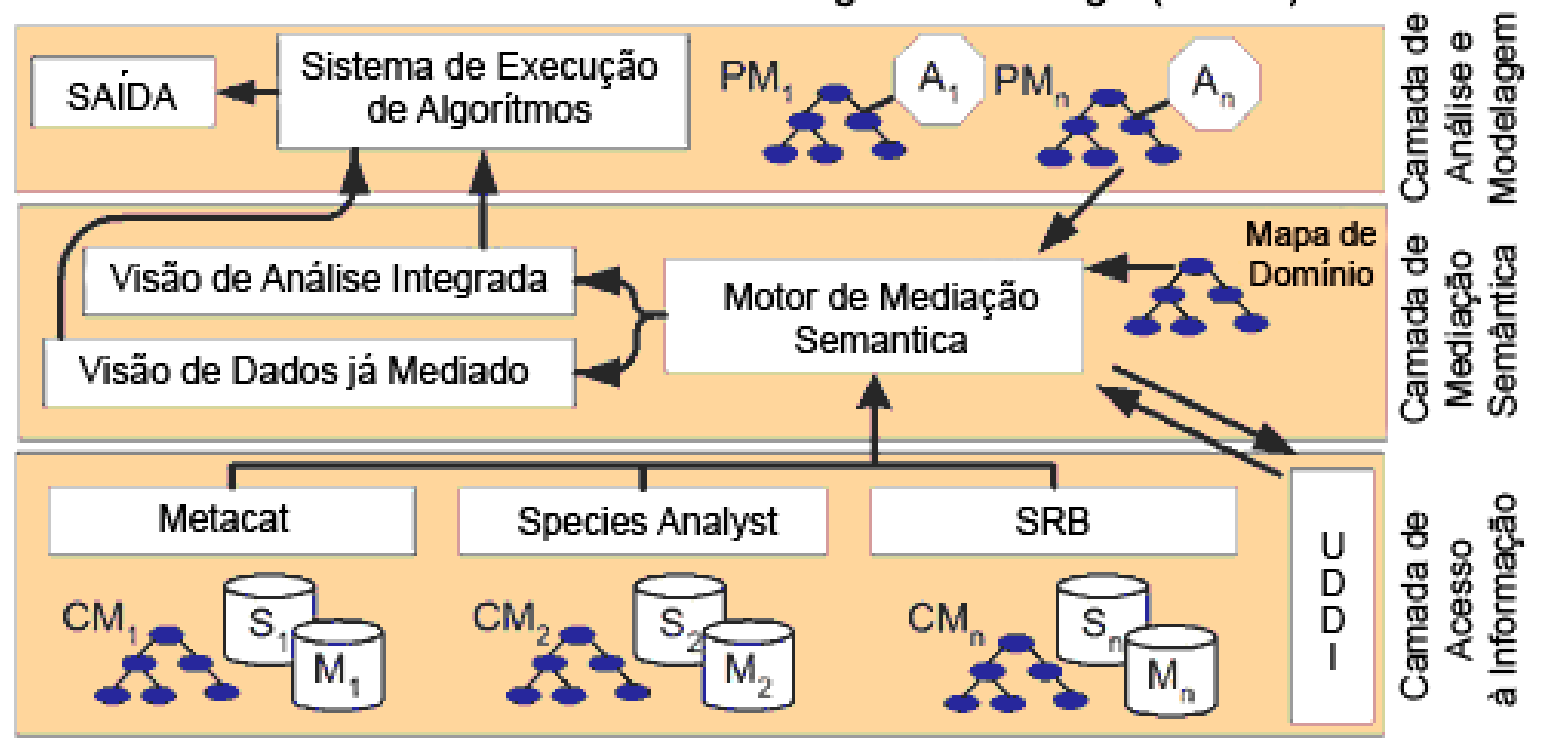

Figura 2.1. Arquitetura utilizada no projeto SEEK, retirada de (PARTNERSHIP FOR BIODIVERSITY INFORMATICS, 2004). 
$\mathrm{Na}$ Camada de Acesso à Informação, o EML (KNB PROJECT, 2005), acrônimo para Ecological Metadata Language, é utilizado para empacotamento (wrapping) dos dados ecológicos das diversas fontes, a fim de permitir sua homogeneização e permitir que os acessos ocorram de maneira uniforme. Uma descrição mais detalhada sobre essa linguagem é apresentada na seção 2.4.4.

\subsection{Componentes de software e serviços}

A seguir são apresentadas algumas ferramentas de software incorporadas ao projeto SEEK, consideradas relevantes para este trabalho.

\subsubsection{Morpho}

Morpho é uma aplicação que permite criar e gerenciar dados e metadados sobre ecologia (HIGGINS; BERKLEY; JONES, 2002). Esta ferramenta foi incorporada a arquitetura do projeto SEEK, porém foi desenvolvida originalmente pelo projeto denominado KNB (Knowledge Network for Biocomplexity - Rede de Conhecimento para Biocomplexidade), envolvendo um consórcio criado em 1999 pelas seguintes instituições de pesquisa norte-americanas: NCEAS (National Center for Ecological Analysis and Synthesis - Centro Nacional para Análises e Sínteses Ecológicas) da University of California em Santa Bárbara, Texas Tech University, LTER (Long Term Ecological Research - Pesquisa Ecológica a Longo Prazo) e o SDSC (San Diego Supercomputer Center), com financiamento da National Science Foundation (Fundação Nacional de Ciência) - NSF.

Um aspecto interessante desta ferramenta é a possibilidade de acessar dados ecológicos situados numa base de dados local, como também acessar bases de dados remotas que tenham sido geradas por outros ecologistas em outros servidores de rede.

A implementação atual do Morpho utiliza a linguagem de programação Java, disponibilizando os seguintes serviços para os usuários:

- criação e edição de metadados;

- pesquisa em coleção de metadados;

- visualização de dados e coleção de metadados; 
- controle de acesso;

- compartilhamento de dados via rede KNB.

A fim de facilitar a captura dos dados de um experimento, um assistente (wizard), conduz o preenchimento de uma tabela. O esquema de dados dessa tabela utilizado pelo assistente pode ser alterado, a fim de se adequar a necessidades específicas eventualmente existentes para uma determinada base de dados ecológica.

Tanto os metadados como os seus dados são agrupados em pacotes (packages), os quais são representados no formato EML (KNB PROJECT, 2005), a ser apresentado na seção 2.4.4. Esta ferramenta também inclui um editor XML para permitir a posterior inclusão de campos não utilizados pelo assistente.

Uma crítica que cabe a esta ferramenta é o fato de não fazer a validação dos dados entrados, em especial os taxonômicos, uma vez que a validação de dados biológicos ou ecológicos é uma preocupação antiga de usuários dessa categoria de aplicações (MALCOLM; HESS, 1976). Por exemplo, se ao catalogar os dados de uma observação, um ecologista digitar o nome científico de uma espécie de maneira errônea, não há correção ou mesmo qualquer alerta sobre tal fato.

As buscas no Morpho são feitas a partir de três tipos de parâmetros: assunto (titulo, resumo, palavras-chave), dados taxonômicos das espécies envolvidas ou utilizando dados geográficos (spatial, no software), a qual permite delimitar uma área retangular definida pelos seus limites de latitude e longitude, que servirá como referência para localização das observações. A Figura 3 mostra uma interface de usuário para pesquisa geográfica no Morpho. As pesquisas podem ser combinadas para buscas por um ou mais parâmetros descritos acima. Além disso, existem ainda as opções de busca na base de dados local e/ou numa base de dados remota. Quando uma busca envolve acesso a bases de dados remotas, entra em ação a ferramenta Metacat, descrita a seguir.

\subsubsection{Metacat}

Metacat é uma abreviação para "Metadata Catalog - Catálogo de Metadados" para a ferramenta de software desenvolvida pelo NCEAS para o projeto KNB. No âmbito do projeto SEEK, o Metacat é utilizado como um repositório dos 
dados/metadados gerados a partir do Morpho. Porém, o Metacat é um banco de dados em XML, independente do esquema, e assim permite armazenar diferentes esquemas em XML, e não somente aqueles utilizados pelo Morpho (JONES et al., 2001).

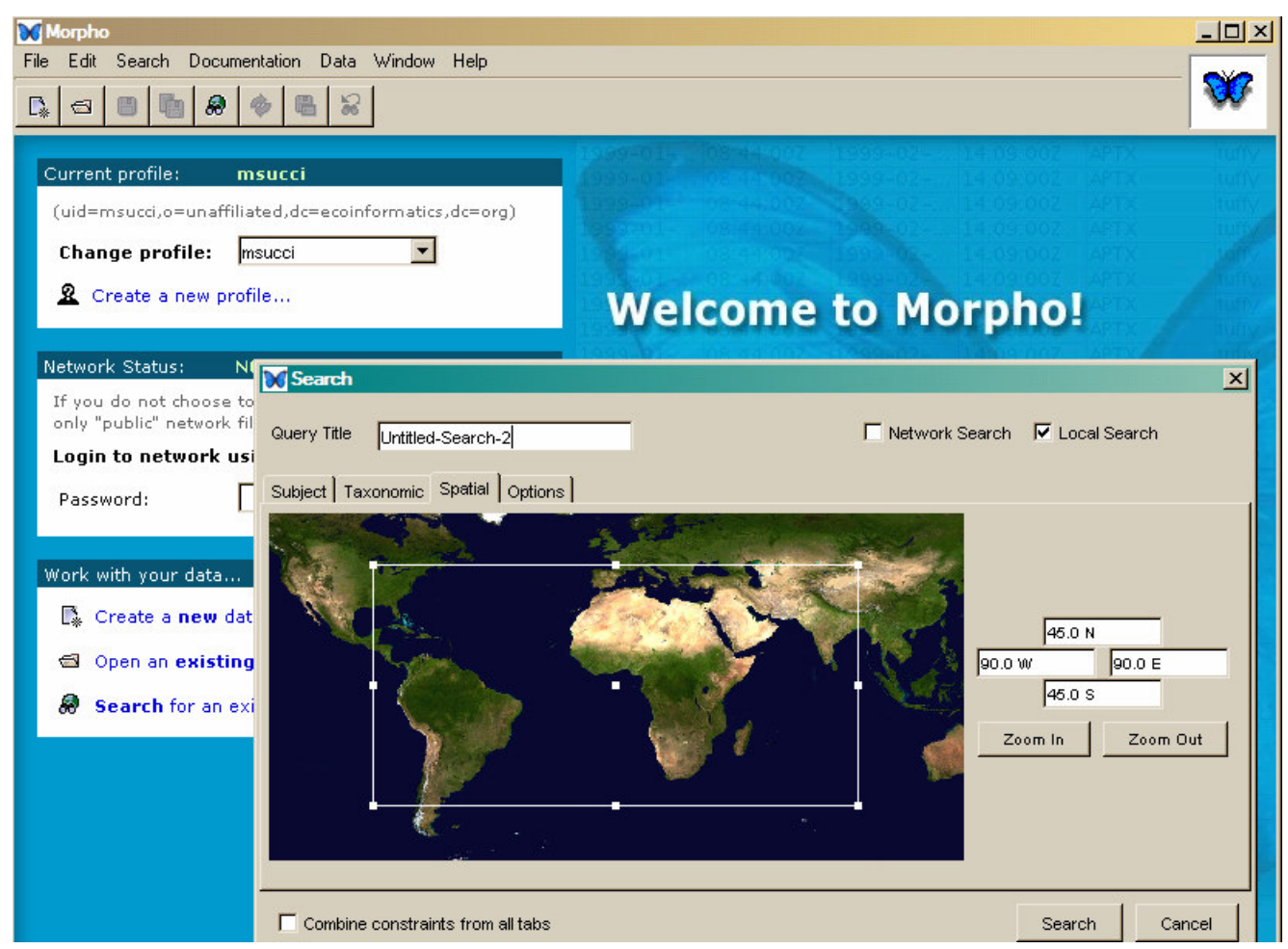

Figura 2.2. Tela de pesquisa geográfica do MORPHO.

A implementação atual é constituída por um servlet em linguagem Java ("Servidor Metcat"), que faz o processamento dos dados recebidos em XML. Os metadados são tratados serializados pelo servidor Metcat e armazenados em um banco de dados relacional, ficando os dados disponíveis para posterior acesso.

A comunicação entre o servidor Metacat e um cliente é feita pelo método POST (FIELDING, 1999) do protocolo HTTP para a realização de operações de inserção, atualização e remoção de pacotes. $O$ documento $X M L$ é passado como um parâmetro do tipo seqüência de caracteres ("string"). Se também for enviado um DTD (Document Type Definition) ele é usado para a validação do documento XML.

Para o controle de acesso, o Metacat utiliza um esquema LDAP (Lightweight Directory Access Protocol) para efetuar o serviço de autenticação do requisitante dos 
documentos. O controle de acesso é feito por meio de ACLs (Access Control List), as quais descrevem os direitos (escrita, leitura, troca de permissão) sobre o documento.

Os dados do pacote podem ser armazenados localmente, no próprio documento XML, ou externamente. Neste último caso, são acessíveis via o servidor Metacat, que neste caso age como um proxy para recuperar o conteúdo remoto. $\mathrm{Na}$ versão estudada (1.6.0), foi implementado no servidor Metacat somente o serviço proxy para o protocolo HTTP.

A Figura 2.3 mostra a integração do Morpho com o Metacat. O módulo "adaptador FS" integra , quando necessário, o proxy descrito no parágrafo anterior.

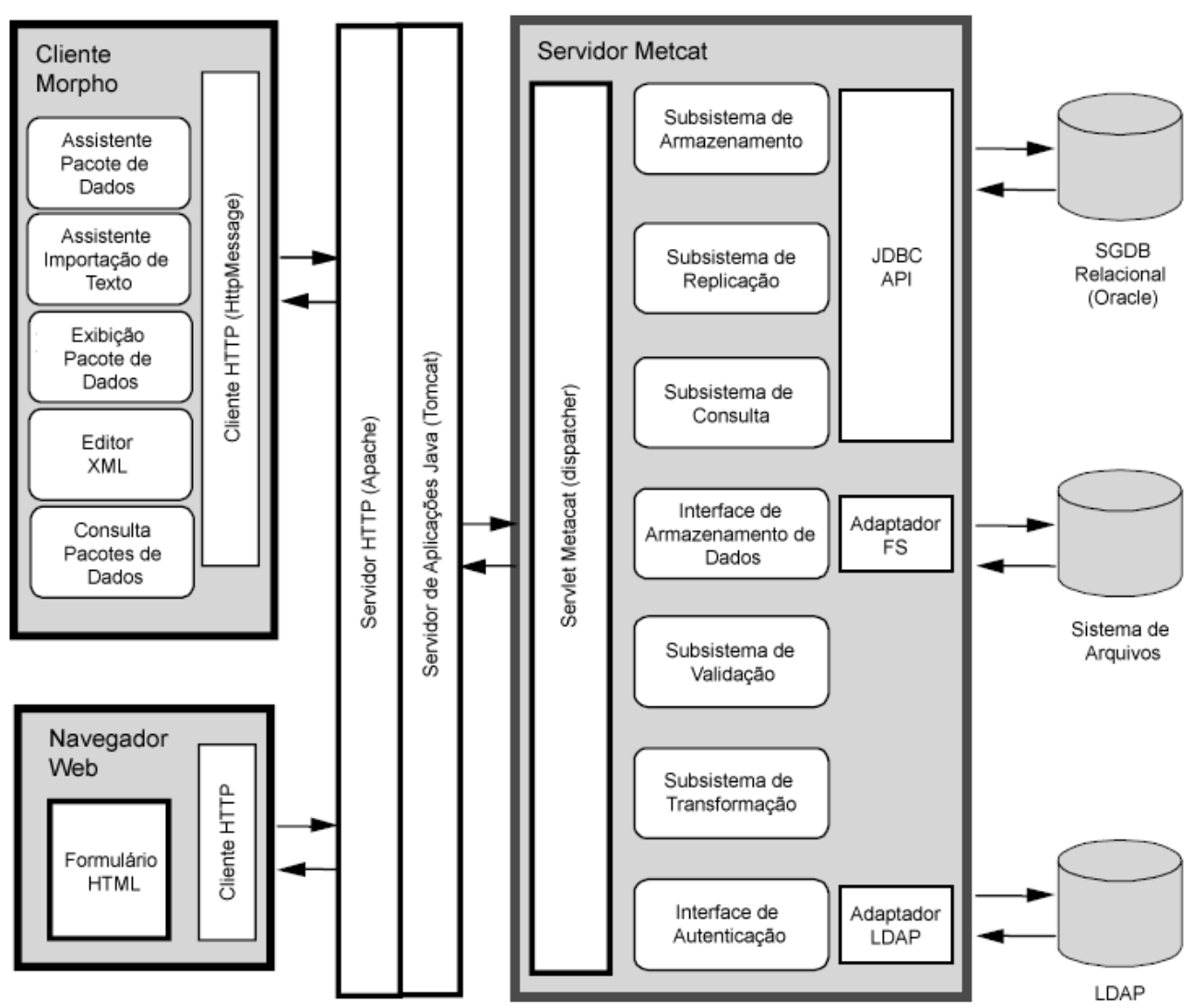

Figura 2.3. Integração Morpho e Metacat . Extraído de (HIGGINS; BERKLEY; JONES, 2002). 


\subsubsection{Kepler}

Kepler (ALTINTAS, 2004) é uma aplicação baseada em Java que executa análises envolvendo coleções e dados ecológicos, permitindo a modelagem da seqüência de processos utilizada em análises científicas, baseado no sistema Ptolemy (HYLANDS et al., 2003). Atualmente o Kepler é desenvolvido por membros de outros projetos científicos, além do projeto SEEK.

As principais características do Kepler são:

- uso de uma interface amigável para a modelagem da seqüência de processos (Figura 2.4);

- composição de serviços, utilizando Web Services (seção 2.5), permitindo assim a execução distribuída de tarefas em um Grid computacional;

- o acesso a base de dados e também a dados descritos em pacotes EML (seção 2.4.4) de forma automática. Dados armazenados em outros formatos também podem ser obtidos por meio do Ecogrid (seção 2.5).

A flexibilidade do Kepler e suas potencialidades o tornam adequado também para o uso em outras áreas do conhecimento além da Ecoinformática. Exemplos de uso em áreas tão diversas como Biologia Molecular, Geologia, Oceanografia e Química são mostrados em (KEPLER; 2006). Já Klasky; Ludaescher; Parashar (2006) propõem uma extensão do Kepler para uso em Física Nuclear. 


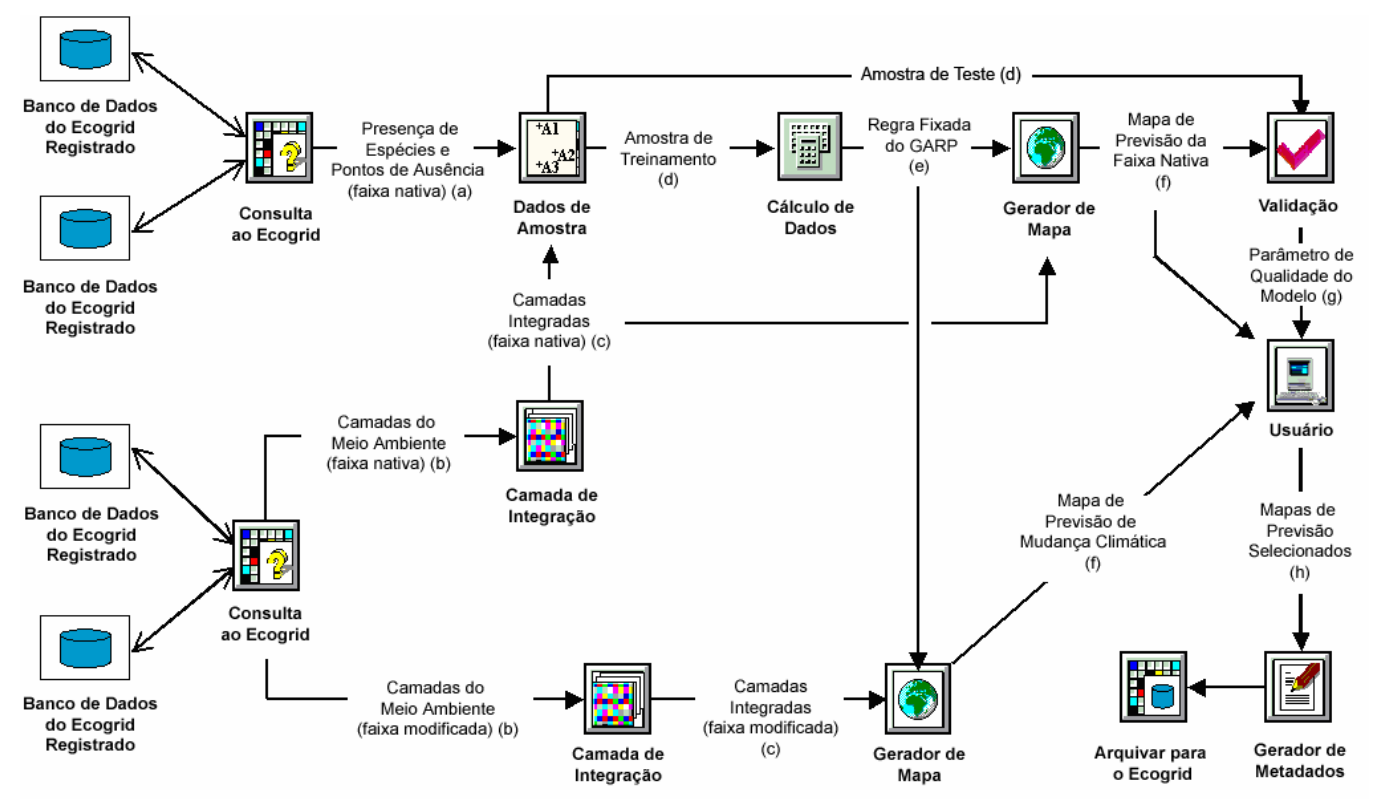

Figura 2.4. Exemplo de tela de desenho da seqüência de processos da aplicação Kepler para geração de dados no estudo de ocorrência de espécies utilizando o GARP (Genetic Algorithm for Rule Processing - Algoritmo Genético para Processamento de Regras). Extraído de (KEPLER; 2006).

\subsection{WebBee}

WebBee é um sistema de informações sobre biodiversidade de abelhas, envolvendo espécies do Brasil. De acordo com Saraiva et al. (2003), foi desenvolvido com o objetivo de organizar o conhecimento e facilitar a distribuição de informações sobre estes insetos.

O sistema é composto por três módulos: Manutenção, Serviços e Web. Estes módulos operam sobre um banco de dados, o qual armazena informações sobre abelhas brasileiras e plantas visitadas por estas espécies. A Figura 2.5 mostra um diagrama Entidade-Relacionamento com o Esquema da base de dados do sistema. 


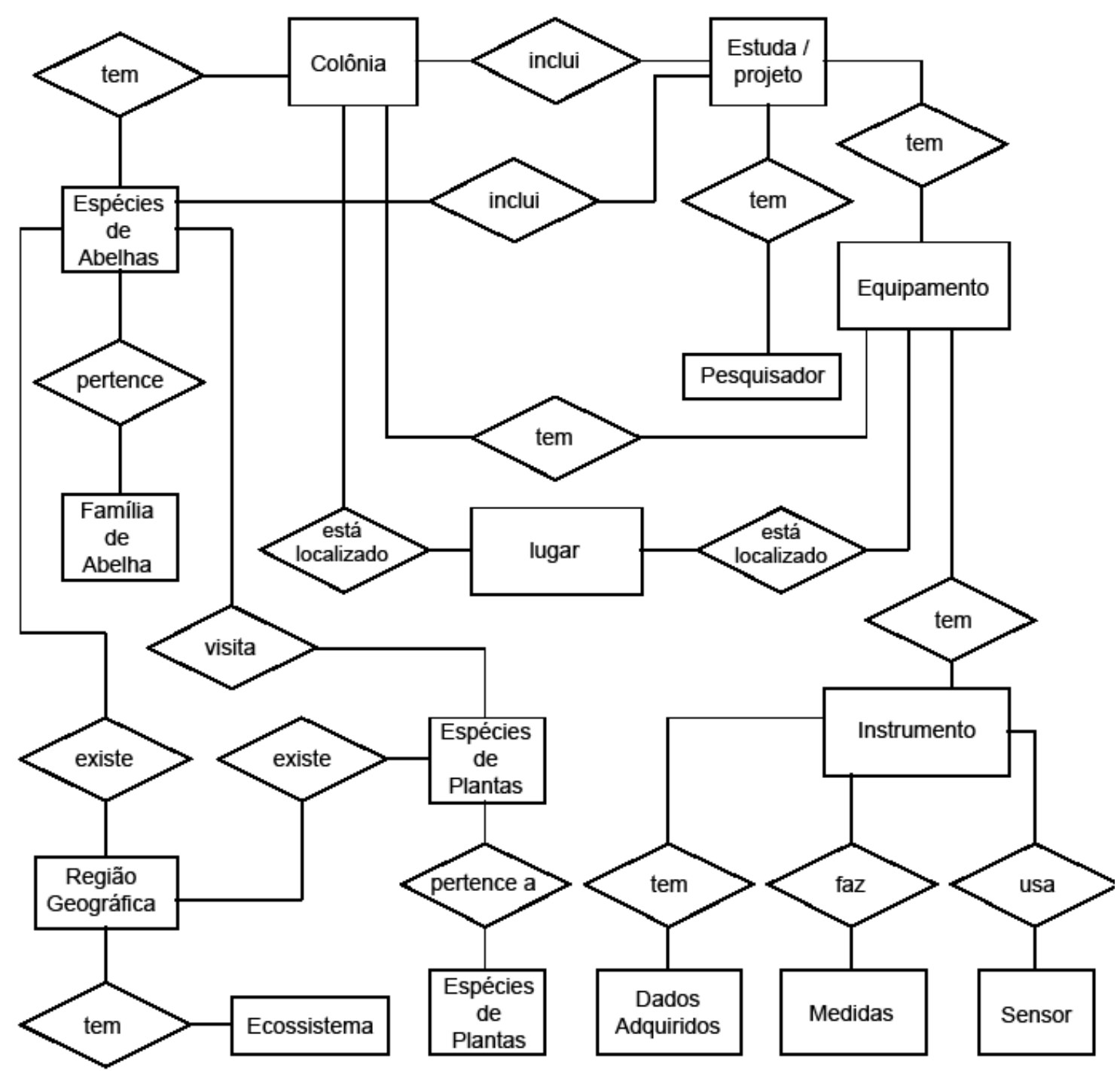

Figura 2.5. Sistema Webbee - Diagrama Entidade-Relacionamento Simplificado do banco de dados. Extraído de (SARAIVA et al., 2003).

Por meio do módulo Web, os dados estão disponíveis através de fichas, as quais podem ser acessadas através de consultas pelo Nome Científico ou Nome Popular das espécies (abelhas ou plantas) envolvidas. 


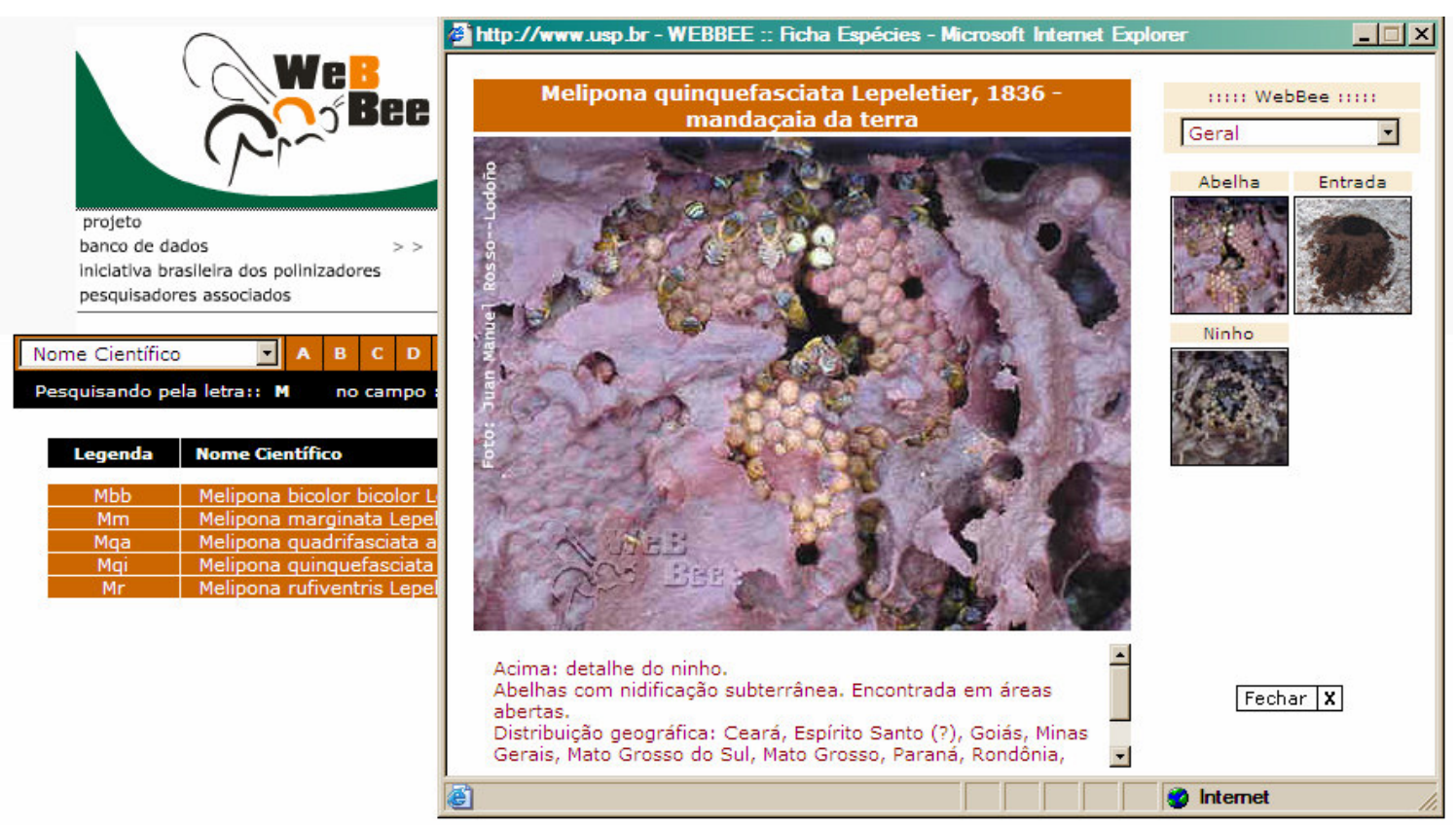

Figura 2.6. Sistema Webbee - Ficha da espécie Melípona quinquefasciata Lepeletier (mandaçaia da terra).

As fichas (Figura 2.6) apresentam fotos das colméias ou de espécimes (abelhas), através de imagens que mostram detalhes sobre o ninho, operárias, rainha, machos da espécie, além de plantas visitadas.

Além das facilidades de consultas a este banco de dados, o sistema contém também páginas de auxílio à classificação taxonômica de espécies de abelhas brasileiras e informações sobre meliponicultura.

\subsection{Padrões de metadados de biodiversidade}

Metadados podem ser definidos como "dados sobre dados" (BERNERS-LEE, 1997), ou seja, dados que descrevem e classificam outros dados. Michener (1997) relaciona os benefícios da utilização de metadatos, destacados a seguir:

- identificação e aquisição de dados para um domínio específico de aplicação, período de tempo ou localização geográfica;

- determinação da adequabilidade do dados para um objetivo específico;

- processamento, análise e modelagem de dados. 
Em ambientes onde há grande heterogeneidade nos dados tratados, o uso de metadados permite relacionar dados através de uma classificação que seja comum entre os diversos tipos de dados disponíveis, a fim de melhorar a integração e compartilhamento destes dados. Nas disciplinas relacionadas à Biologia e à Ecologia, o uso de metadados vem ao encontro destas necessidades, uma vez que os dados tratados podem estar armazenados em muitas formas diferentes - desde fichas manuscritas até em banco de dados distribuídos em uma rede de computadores. Em especial na área da Ecologia, pela sua natureza interdisciplinar (MICHENER et al. 1997), os dados tratados em um experimento podem ser tão diversos que vão desde a classificação taxonômica de um espécime observado até nas medidas de umidade da região onde o foi espécime foi localizado.

A seguir são examinados quatro padrões de metadados relativos à biodiversidade : DarwinCore, $A B C D$, PlinianCore e EML. Os dois primeiros são adotados nas redes mais importantes de dados de coleções biológicas; o terceiro é um novo padrão adotado pelo INBIO (Insituto Nacional de Biodiversidad) da Costa Rica para uso na REyE (Red de Especies y Especímenes - Rede de Espécies e Espécimes) do IABIN (Inter-American Biodiversity Information Network). O último é o utilizado no projeto SEEK, descrito anteriormente.

\subsubsection{DarwinCore}

O Darwin Core é um padrão de metadados, baseado em XML projetado para permitir a integração de dados de biodiversidade, buscando os elementos comuns aos registros de coleções de espécimes e também de observações de espécimes na Natureza, a fim de permitir a pesquisa e posterior recuperação destes dados (VIEGLAIS, 2003). Segundo Wieczorek (2006) é "uma especificação de conceitos e estrutura de dados que pretende dar suporte à recuperação e integração de dados primários que documentam a ocorrência de organismos no espaço e tempo e a ocorrência de organismos em coleções biológicas".

O Darwin Core surgiu inicialmente como um produto do projeto The Species Analyst (SPECIES ANALYST, 2006) da Universidade do Kansas. A versão 1.2.1 do DarwinCore é a mais utilizada atualmente. Ela foi desenvolvida paralelamente ao protocolo DiGIR (DIGIR-b, 2006) e utilizada inicialmente pelo projeto MaNIS (WIECZOREK-b, 2006) da Universidade da Califórnia em Berkeley (USA). Esta 
versão também encontra-se em uso pela redes GBIF (GBIF, 2006), HerpNet (HERPNET, 2006), OrNIS(ORNIS, 2006), e FishNet2 (FISHNET2, 2006). Uma extensão do núcleo do Darwin Core deu origem ao padrão OBIS (Ocean Biogeographic Information System) (OBIS, 2006), utilizado no sistema de mesmo nome.

O Darwin Core, abreviado normalmente como DwC, é adotado pelo TDWG (Taxonomic Database Working Group - Grupo de Trabalho de Banco de Dados Taxonômicos) uma entidade cujo objetivo é estabelecer colaboração internacional entre projetos de banco de dados e é filiada à IUBS (International Union of Biological Sciences - União Internacional de Ciências Biológicas). O padrão está sob revisão neste grupo desde 2004 para o lançamento de uma nova versão.

O protocolo utilizado para consultas em redes que utilizam o Darwin Core é chamado DiGIR (Distributed Generic Information Retrieval - Recuperação de Informação Genérica Distribuída) e permite que bancos de dados de biodiversidade distribuídos sejam consultados como se fossem um só banco de dados virtual. O DiGIR, no entanto, serve para consultas distribuídas a outros bancos de dados além daqueles relacionados à biodiversidade.

\subsubsection{ABCD}

O padrão ABCD (Access to Biological Collections Data - Acesso a Dados de Coleções Biológicas) (ABCD, 2006) é um padrão também baseado em XML, criado com os mesmos objetivos do Darwin Core, isto é, troca e compartilhamento de dados e metadados de coleções biológicas e também de observações de espécimes na natureza.

Este padrão foi desenvolvido a partir de 2002 e seu uso inicial ocorreu no projeto BioCASE (Biological Collection Access Service for Europe - Serviço de Acesso a Coleções Biológicas para Europa). Atualmente também é adotado como padrão pelo GBIF, de forma que provedores da rede BioCASE também podem unirse à Rede GBIF. A versão atual (2.06) é um padrão que teve aprovação recomendada, mas ainda não aceita pelo TDWG (até janeiro de 2007). Uma extensão do padrão ABCD chamada ABCDEFG ( $A B C D$ Extended For Geosciences $A B C D$ Estendido Para Geociências) é utilizada pela rede européia GeoCASE 
(Geosciences Collection Access Service - Serviço de Acesso a Coleção de Geociências), conforme GeoCASE (2006).

\subsubsection{Plinian Core}

O Plinian Core é um padrão proposto pelo Instituto Nacional de Biodiversidade da Costa Rica para a documentação de espécies, com o objetivo de recuperar informações de espécies distribuídas em banco de dados. Com relação a esse padrão, deve-se ressaltar a diversidade de dados tratados para representação de espécies. Segundo Mora (2006), os seguintes conceitos estão previstos no padrão (nomes entre parênteses referem-se a exemplos de campos):

- Origem da Informação (Código da Instituição);

- Informação Taxônomica (Nome científico);

- Informação da Página/Registro (Idioma, Autores, Data de publicação);

- Descrição (Hábitos, Ciclo de Vida, Relações);

- Demografia e Conservação (População, Habitat, Legislação envolvida);

- Distribuição (Países);

- Usos e Folclore (Usos documentados);

- Outros (Referências gerais, Multimídia relacionada).

\subsubsection{EML}

O EML (Ecological Metadata Language - Linguagem de Metadados Ecológicos) é um padrão de XML usado para catalogar informação sobre dados ambientais e ecológicos, e foi desenvolvido pela projeto $\mathrm{KNB}$, descrito anteriormente. O EML visa a padronizar a maneira como esses dados são documentados, a fim de permitir que pudessem ser facilmente entendidos e também integrados de maneira eficiente.

De acordo com KNB Project (2005) este padrão foi desenvolvido a partir dos descritores sugeridos por MICHENER et al. (1997). O conjunto de dados e metadados correspondentes constitui um pacote EML. Um pacote é dividido em módulos, cada um destinado a conter um tipo de informação. A estrutura de um pacote e as descrições dos principais módulos são apresentadas na Figura 2.7. 


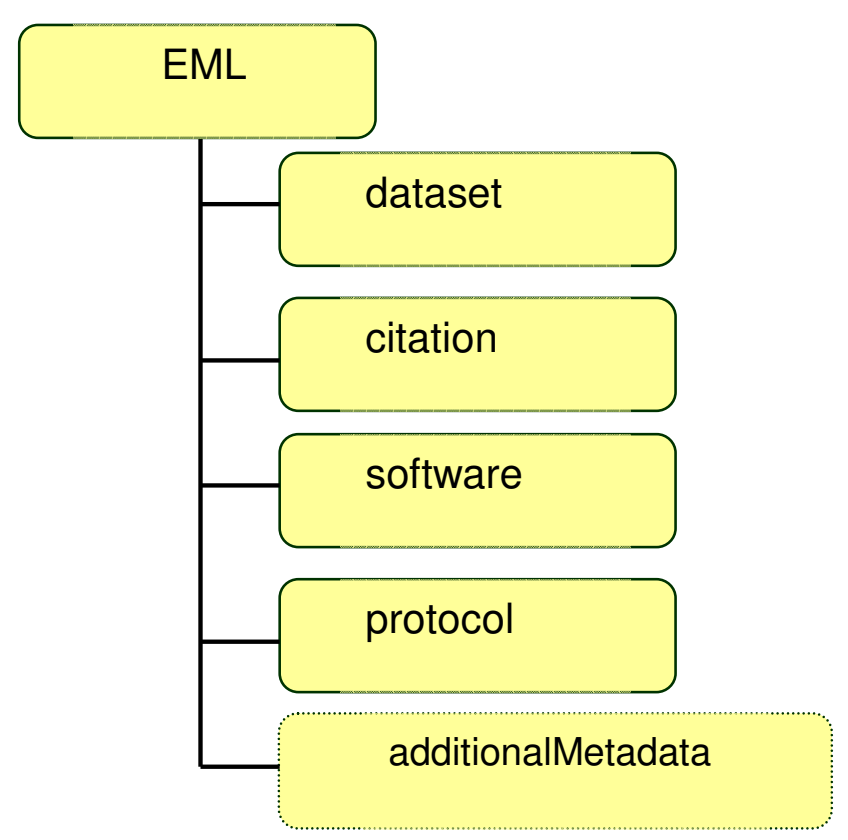

Figura 2.7. Estrutura de um pacote EML com a representação dos principais módulos.

Os módulos de nível mais alto disponíveis para um pacote EML, com os dados por eles descritos, são mostrados abaixo:

- dataset - conjunto de dados, podendo incluir por exemplo conjuntos de tabelas e/ou imagens vetoriais. Contém também, entre outros, metadados sobre a localização geográfica e temporal dos dados, além de informações sobre as pessoas de contato, os métodos utilizados, e uma lista relacionando indivíduos ou grupos às permissões concedidas para acesso aos dados;

- citation - referência (artigo, livro, anais de congressos, etc.) ;

- software - softwares utilizados (plataforma, sistema operacional, versão, dependências, etc.);

- protocol-procedimentos usados no experimento.

Em um pacote de dados, alguns módulos são obrigatórios, por serem considerados essenciais para a identificação do pacote, enquanto outros são opcionais, com informação extra. Outros metadados que não estejam no formato EML podem ser incluídos com o uso do módulo additionalMetadata, tornando a 
linguagem extensível, pela inclusão de qualquer outro tipo de metadado baseado em XML. Um exemplo de pacote EML é mostrado na Figura 2.8 .

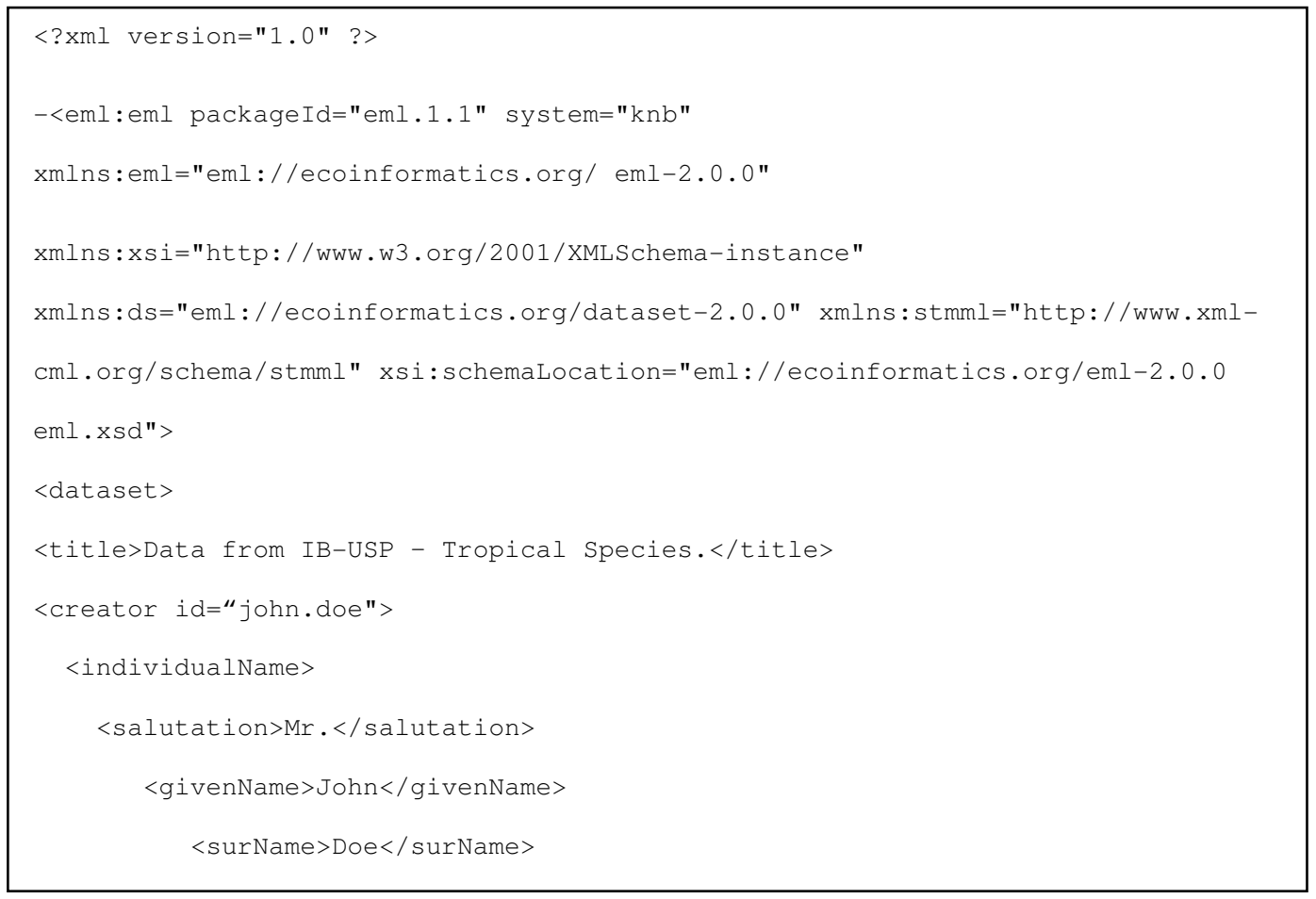

Figura 2.8. Fragmento de um documento EML.

Dentre outros elementos do EML, pode-se destacar o Physical, utilizado para descrever conjuntos de dados e o modo como eles estão armazenados.

\subsubsection{Comparação entre os padrões estudados}

a) ABCD x Darwin Core.

Embora ambos os padrões tenham os mesmos objetivos, eles diferem na maneira como buscam atingi-los. O DwC foi projetado para ser simples, a fim de "reduzir as barreiras para os provedores de acesso e maximizar a disponibilidade para os utilizadores dos dados" (WIECZOREK, 2006), utilizando para atingir esta meta os tipos de dados comuns a todas as coleções/observações de espécimes. $O A B C D$, por sua vez, é mais complexo, e foi planejado para ser "abrangente e geral" (ABCD 2006) e assim procura englobar os tipos de dados presentes nas coleções/observações como um todo. Um exemplo disto é o conjunto de elementos presentes em cada padrão, pois enquanto o Darwin Core trabalha com menos de 50 elementos, na versão 2.06 do ABCD há mais de 1400 elementos disponíveis. Como 
esperado, os elementos do DwC podem, com pequenas restrições, ser relacionados aos do ABCD (BERENDSOHN, 2005).

Os padrões podem ser utilizados de maneira complementar: enquanto a maior leveza do Darwin Core/DiGIR facilita a execução de pesquisa de dados, o padrão BioCase pode ser utilizado para conseguir informação mais detalhada do registro pesquisado.

b) ABCD/Darwin Core x Plinian Core x EML.

Quando se compara os padrões de dados estudados, vemos que uma característica que os diferencia de imediato diz respeito ao objetivo do padrão. Enquanto o Darwin Core e o ABCD tem foco em registros de espécimes (registrados em coleções ou observados na Natureza), o Plinian Core busca descrever registros de espécies. Por sua vez, o EML foi planejado para descrever dados ecológicos .

A princípio, dados ecológicos podem ser relacionados a dados de observações, como os descritos pelo ABCD/Darwin Core. Porém, o que torna o padrão EML mais adequado para a realização deste trabalho está no fato de que o EML prevê a descrição de dados que podem ser diretamente relacionados a experimentos em um Weblab, como por exemplo :

- autor da pesquisa;

- resumo (abstract);

- espécies observadas na pesquisa;

- métodos utilizados;

- dados obtidos e sua estrutura

Enquanto os outros padrões podem ter previsões que se encaixam bem para os dados que se espera encontrar nos Weblabs, como por exemplo "autor da pesquisa/observação" e "espécie observada", é de especial importância para este trabalho o tratamento que o EML e ferramentas associadas podem proporcionar aos dados que se esperam coletar em um Weblab. Assim, dados de temperatura e umidade coletados em uma colônia de abelhas durante um experimento, por exemplo, são adequadamente documentados no EML; os outros padrões vistos, até por metas de projeto, não representam de maneira adequada esses dados. 
Adicionalmente, o uso do EML neste trabalho também proporciona naturalmente a integração com a ferramenta Metacat para o armazenamento das informações obtidas durante os experimentos. Como decorrência disso, o software Morpho também pode ser utilizado neste projeto.

Mais importante, porém, é que o uso do Metacat para o registro desses dados torna possível a integração com o Ecogrid da arquitetura do SEEK, e consequentemente torna possível o uso do software Kepler para análises dos dados coletados. O controle de acesso aos dados registrados, um dos requisitos para os Weblabs, também é proporcionado a partir da utilização do EML.

\subsubsection{Protocolos DiGIR, BioCASE e TAPIR}

Nas redes de biodiversidade, protocolos são utilizados em conjunto com os padrões de metadados para a transferência de informações. O protocolo DiGIR (DiGIR-b) é usado nas redes que adotam o DwC, enquanto o protocolo BioCASE é utilizado na rede de mesmo nome.

A fim de permitir a integração das principais redes de biodiversidade, foi proposta em 2004 a criação de um novo protocolo que pudesse ser usado tanto nas redes que utilizassem o BioCase quanto o DiGIR. Este protocolo chama-se TAPIR (TDWG Access Protocol for Information Retrieval - Protocolo de Acesso para Recuperação de Informação do TDWG) (TAPIR, 2006) e procura combinar as funcionalidades dos outros dois protocolos. Atualmente encontra-se em fase de especificação e testes iniciais.

\subsection{Arquitetura Orientada a Serviços e Web Services}

No contexto de Sistemas Distribuídos, um modelo utilizado é o de Arquitetura Orientada a Serviços, também conhecido pelo acrônimo SOA (Service Oriented Architecture). De acordo com Barry and Associates (2004) serviços são funções bem-definidas as quais não dependem do contexto ou estado de outros serviços e $S O A$ é um conjunto de serviços, expostos de forma que podem ser compostos para a criação de funções mais complexas.

Uma Arquitetura Orientada a Serviços fornece padrões para o projeto, desenvolvimento, implantação e gerenciamento de uma infra-estrutura de aplicações 
fracamente acopladas (loosely coupled). Neste paradigma, o nível inferior da arquitetura é composto por serviços básicos, suas descrições e operações primitivas (publicação, descoberta, seleção e utilização). Camadas superiores da arquitetura fornecem os meios para a composição e o gerenciamento destes serviços. (PAPAZOGLOU; GEORGAKOPOULOS, 2003).

O uso de uma arquitetura baseada em serviços possibilita, entre outras vantagens, melhorias nos aspectos de flexibilidade do sistema, melhor escalabilidade e entrega de soluções de forma mais rápida e eficiente. Há várias formas de permitir acessos aos serviços, mas a mais promissora é o uso da tecnologia de Web Services.

Uma definição de Web Services, segundo W3C (2003) é reproduzida abaixo:

Um Web service é um sistema de software identicado por uma URI, cujas
interfaces públicas e ligações são definidas e descritas usando XML. Sua
definição pode ser descoberta por outros sistemas de software. Estes
sistemas podem interagir com o Web Service de forma prescrita por sua
definição, usando mensagens baseadas em XML e transportadas por
protocolos de Internet.

Embora completa, esta definição pode ser pouco esclarecedora. Podemos definir Web Services como "serviços" que podem ser acessados de "forma padronizada" "via Internet", por usuários ou por outros programas. Quatro aspectos importantes podem ser destacados a partir desta definição:

- Serviços: Web Services são programas que fornecem uma unidade de trabalho a um outro programa (o consumidor do serviço) de forma a atingir determinados resultados finais. O serviço pode ser consumido por outros programas consumidores, em eventuais outros sistemas, permitindo o reuso do código de forma transparente;

- Forma padronizada: a utilização de Web Services coloca padrões para a comunicação entre programas e para a pesquisa de serviços. Esta padronização é discutida nos próximos parágrafos;

- Via Internet: a comunicação via Web Services é feita pela Internet, aproveitando assim as vantagens de uma rede de grande capilaridade e de baixo custo de utilização;

- Por outros programas: no âmbito de Web Services, a comunicação é prevista para ocorrer essencialmente entre programas, não entre usuário e programa como na Internet habitual. 
A Figura 2.8 mostra um diagrama representativo da utilização de Web Services. Temos um fornecedor de serviço, i.e., alguém que produziu um programa que pensa ser de interesse de outros, que publica (passo 1) uma descrição sua e também dos serviços oferecidos em um diretório de serviços. Quando alguém quer utilizar um determinado serviço - o consumidor do serviço- faz uma pesquisa no diretório buscando o serviço desejado (passo 2) e recebe o resultado (passo 3). A partir daí, há o estabelecimento de uma comunicação entre o provedor e o consumidor do serviço (passo 4), na qual existe inicialmente uma consulta ao fornecedor do serviço sobre quais são os parâmetros que devem ser enviados $e$ como os resultados serão retornados. A partir daí, ocorre o uso propriamente dito do serviço, com o consumidor enviando os parâmetros do serviço e o provedor fornecendo os resultados correspondentes.

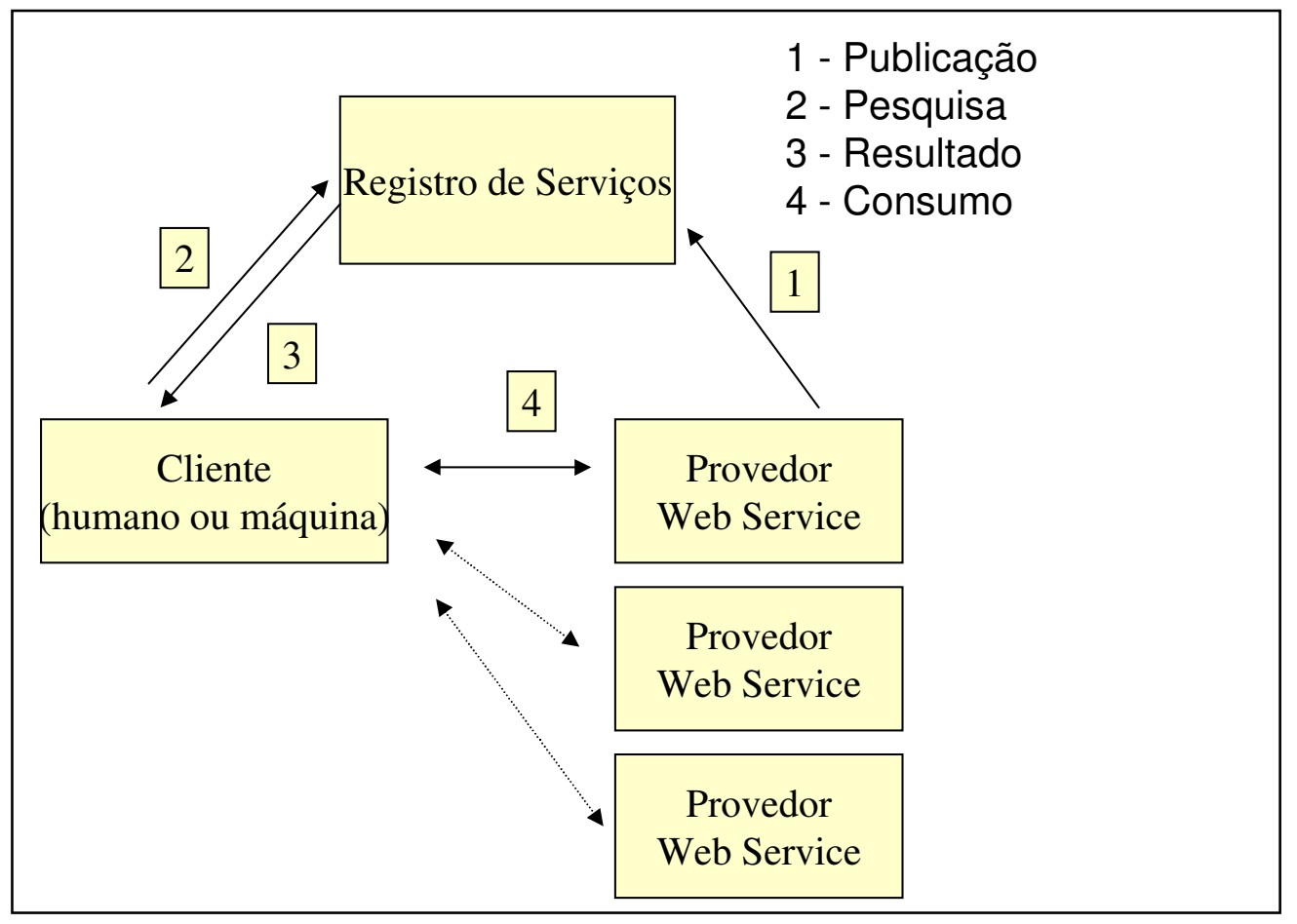

Figura 2.9. Diagrama representativo da arquitetura de Web Services.

De acordo com Stutor (2003) e Tittel (2001) a vantagem na utilização de Web Services está nos padrões determinados pela tecnologia, a saber: 
- padrão utilizado para a comunicação entre os serviços : XML (eXtended Markup Language) um formato de dados para troca estruturada de documentos;

- formato do envelope para a troca de mensagens : SOAP (Simple Object Access Protocol) -um mecanismo o qual permite a definição de mensagens request-response, usando preferencialmente HTTP (Hyper Text Transfer Protocol), ou também outros protocolos tais como FTP (File Transfer Protocol) ou SMTP (Simple Mail Transfer Protocol). A vantagem da utilização destes protocolos, em especial o HTTP, está na baixa probabilidade de ocorrerem problemas com dispositivos de proteção de redes tais como Firewalls;

- a linguagem que descreve como comunicar-se com o serviço: WSDL (Web Services Description Language) - descreve os serviços, parâmetros e a localização, usando um modelo de descrição neutro em relação a implementação específica do cliente/servidor;

- modo de publicar e descobrir o serviço desejado:UDDI (Universal Description, Discovery and Integration) - um diretório baseado em XML para a listagem de negócios onde os provedores de serviço registram os serviços disponíveis e sua localização.

\subsection{SNMP}

O SNMP (Simple Network Management Protocol - Protocolo Simples de Gerência de Rede) (CASE et al., 2002) é um dos padrões mais importantes para gerenciamento de rede, sendo o mais amplamente usado (KUROSE, ROSS; 2006). Ele é utilizado na arquitetura SNMP, a qual é baseada em cinco elementos, a saber :

- objetos gerenciados, correspondentes aos dispositivos físicos da rede a serem controlados;

- um módulo gerente, que faz a interface entre o elemento humano que gerencia a rede e o restante do sistema; 
- módulos agentes, responsáveis pelas interfaces entre o restante do sistema de gerenciamento e os objetos gerenciados;

- MIB (Management Information Base - Base de Informações de Gerenciamento), uma base de dados que representa o estado geral dos elementos gerenciados;

- o protocolo SNMP, utilizando entre o gerente e os agentes para requisição de estados e configurações nos objetos gerenciados.

A MIB é uma "coletânea de objetos gerenciados que, juntos, formam um banco virtual de informações virtuais" (KUROSE, ROSS; 2006). Como exemplos, podemos ter na MIB informações numéricas, como o número de pacotes descartados em uma determinada conexão por um roteador, ou descritivas, tal como a versão do software que está sendo rodado em um servidor (KUROSE, ROSS; 2006).

Paras operações de gerenciamento, como já citado, são utilizadas cinco operações básicas do SNMP. São elas (CASE et al, 2002):

- GET, GET-NEXT - enviado pelo gerente ao agente para obter o estado de uma ou mais variáveis gerenciadas;

- GET-RESPONSE - enviado pelo agente ao gerente como resposta a um GET ou GET-NEXT, com as informações solicitadas, ou uma mensagem de erro caso não seja possível obtê-las;

- SET - enviado pelo gerente ao agente para alteração de alguma variável;

- TRAP - enviado pelo agente ao gerente caso algum evento préespecificado ocorra, sendo útil para a criação de alarmes de gerenciamento.

A Figura 2.10. mostra os elementos utilizados na arquitetura SNMP. O paradigma da arquitetura SNMP é utilizado neste trabalho para comunicação com os instrumentos dos weblabs. 


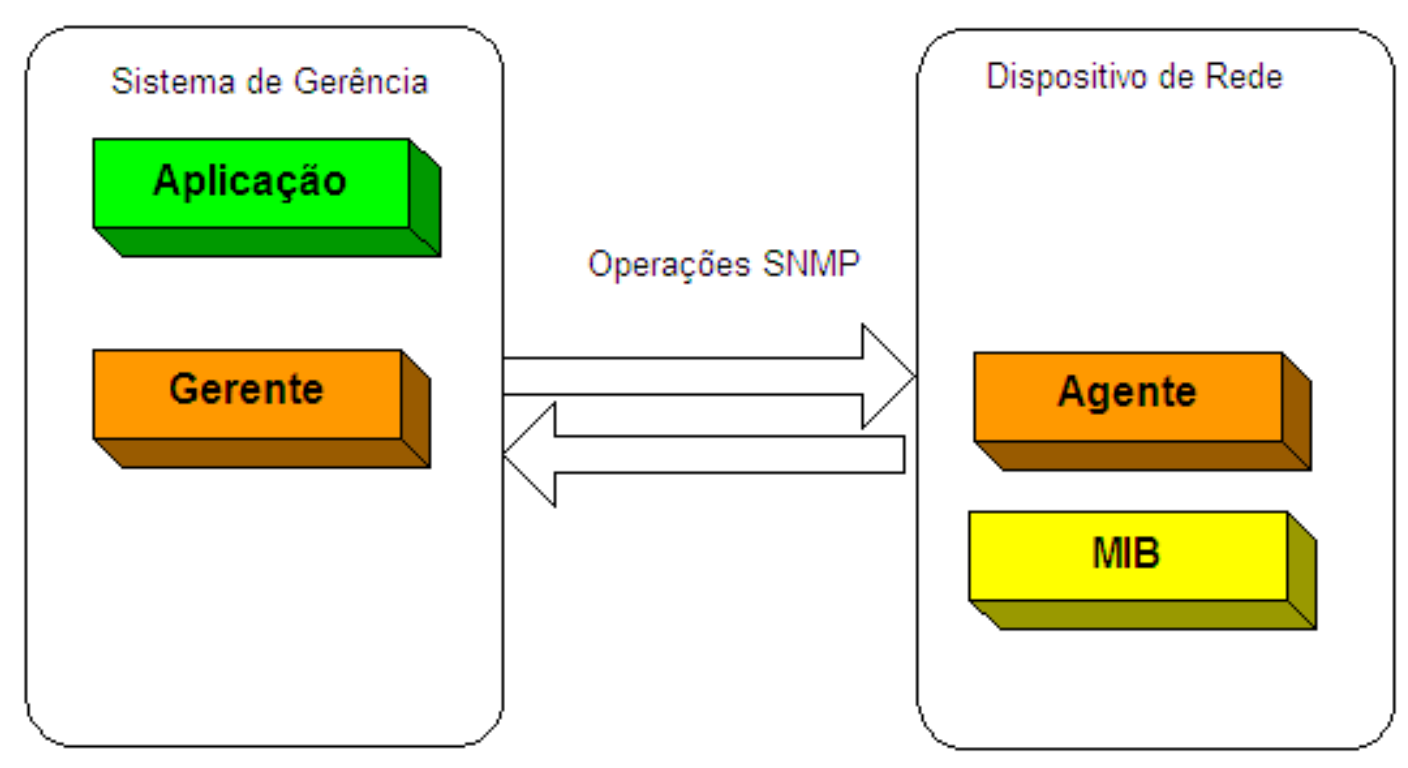

Figura 2.10. Principais elementos da Arquitetura SNMP 


\section{Weblabs e trabalhos relacionados}

Neste capítulo são apresentados os conceitos de weblab e outros relacionados a ele. Em seguida uma breve apresentação do projeto ViNCES e do Laboratório de Abelhas, que servirá para estudo de caso da arquitetura proposta, também é feita. Por fim, são mostradas os principais tipos de arquiteturas utilizadas para a disponibilização de weblabs.

\subsection{Laboratórios Reais $\mathrm{x}$ Virtuais $\mathrm{x}$ Remotos}

Laboratórios para a realização de experimentos são essenciais em muitas atividades de Ciência. No entanto, os custos relativos à aquisição e montagem da estrutura física do laboratório às vezes tornam-se um fator inibidor para a sua criação, o que pode acarretar prejuízos a estudantes e pesquisadores. Algumas outras características inerentes a um laboratório "real" podem constituir desvantagens, quando se compara àquelas de um laboratório virtual ou remoto, como visto mais à frente. Dentre elas, incluem-se a necessidade do experimento ter que ser realizado de maneira inerentemente presencial e também de acordo com limites de horários impostos pela instituição responsável pelo laboratório. Também pode ser citada a necessidade de mais espaço físico caso se queira um maior número de estudantes/pesquisadores realizando experimentos simultaneamente.

Para efeitos educacionais, o uso de experimentos gravados em vídeo pode ser uma alternativa ao uso de uma laboratório "real" (NEDIC;MACHOTKA; NAFALSKI, 2003; DENIZ;BULANCAK;OZCAN, 2003), com grandes ganhos em relação à custo, horários, locais e escalabilidade. No entanto, a falta de interatividade é claramente um problema desta opção.

Com a evolução da capacidade de processamento e das técnicas de computação gráfica, uma outra alternativa que pode ser oferecida é utilização de simuladores (DENIZ;BULANCAK;OZCAN, 2003; CHIRICO,SCAPOLLA, BAGNASCO, 2005) - programas de computador os quais pretendem reproduzir o comportamento de determinadas situações no mundo real - para a realização de experimentos. Um laboratório baseado em simuladores pode ser chamado de virtual lab - laboratório 
virtual (NEDIC;MACHOTKA;NAFALSKI, 2003 ; KIKUCHI et al. 2004; YAN et al.,2006), embora o termo seja eventualmente usado para laboratórios remotamente controlados (KIKUCHI et al. 2004, CHIRICO;SCAPOLLA; BAGNASCO, 2005), dos quais se trata mais à frente. Em relação a um laboratório real, um laboratório virtual tem vantagens nos aspectos de escalabilidade, flexibilidade de uso e, geralmente, custo.

O uso de simuladores é limitado pela complexidade do ambiente real a ser simulado. Uma boa simulação em geral demanda muito esforço para a geração de modelos matemáticos adequados dos laboratórios simulados (DENIZ;BULANCAK;OZCAN, 2003; KIKUCHI et al.,2004). De maneira geral, a simulação de experimentos envolvendo agentes vivos é complexa. Apesar disso, em casos em que o experimento real for inseguro, ou muito caro ou ainda levar muito tempo, um laboratório virtual deve ser considerado (KIKUCHI et al., 2004).

Conforme citado anteriormente, uma alternativa aos laboratórios reais diz respeito ao uso de um laboratório remoto - remote laboratory ou remote lab (ARPAIA et al., 2000;DENIZ; BULANCAK ;OZCAN, 2003;KHAMIS et al., 2003), com os experimentos sendo realizados à distância através de interfaces que possibilitam a aquisição de dados e o controle das variáveis envolvidas na experiência, sendo, segundo Deniz,Bulancak,Ozcan (2003), uma "síntese da natureza distribuída e interativa dos laboratórios virtuais e da realidade do laboratório local”. Neste caso, quando comparado com um experimento real, há vantagens em relação ao horário/local de utilização e também a um possível aproveitamento mais eficiente da estrutura montada.

Deniz;Bulancak e Ozcan (2003) fazem ainda uma lista das aplicações típicas de laboratórios remotos, classificando-os em diferentes tipos:

- compartilhado : a lógica da construção do laboratório remoto está em compartilhar alguma estrutura e/ou equipamento que são muito caros e/ou raros;

- localizado : neste caso, o laboratório remoto é construído para se permitir a execução de experimentos, feitos normalmente no laboratório real, sem restrições de hora ou local; 
- distante : feito para fornecer conteúdo "prático" para cursos de ensino à distância;

- de "revisão técnica" : montado para permitir o teste e avaliação de vários instrumentos e dispositivos por profissionais de uma determinada área (TECHONLINE, 2006);

Tabela 3.1. Comparação entre diversas classes de laboratórios. Extraído de (NEDIC;MACHOTKA;NAFALSKI, 2003).

\begin{tabular}{|c|c|c|}
\hline Tipo & Vantagem & Desvantagem \\
\hline Real & $\begin{array}{l}\text { - Dados reais } \\
\text { - Interação com equipamento } \\
\text { real } \\
\text { - Trabalho colaborativo } \\
\text { - Interação com supervisor }\end{array}$ & $\begin{array}{l}\text { - Restrições de lugar e tempo } \\
\text { - Caro } \\
\text { - Supervisão é exigida }\end{array}$ \\
\hline Virtual & $\begin{array}{l}\text { - Bom para explicar conceitos } \\
\text { - Sem restrição de lugar e local } \\
\text { - Meio interativo } \\
\text { - Baixo custo }\end{array}$ & $\begin{array}{l}\text { - Dados idealizados } \\
\text { - Falta de colaboração } \\
\text { - Sem interação com o } \\
\text { equipamento real }\end{array}$ \\
\hline Remoto & $\begin{array}{l}\text { - Interação com o equipamento } \\
\text { real } \\
\text { - dados reais } \\
\text { - Sem restrições de lugar e } \\
\text { tempo } \\
\text { - Custo médio }\end{array}$ & - Presença somente virtual \\
\hline
\end{tabular}

Para laboratórios remotos via Internet, pode-se utilizar o termo weblab (DEL ALAMO, 2003). Este é o termo usado no projeto ViNCES e também neste trabalho. 


\subsection{ViNCES}

O programa TiDIA (TIDIA, 2005), Tecnologia da Informação no desenvolvimento da Internet Avançada, patrocinado pela FAPESP, Fundação de Amparo à Pesquisa do Estado de São Paulo, busca mobilizar o meio acadêmico, empresas e governo em projetos cooperativos visando à formação de recursos humanos em grande escala e o avanço da pesquisa científica e tecnológica nesse setor estratégico para a economia, para a ciência e para a sociedade como um todo.

Dada sua manifesta importância estratégica, trata-se de um setor que requer a implantação de um vigoroso sistema de pesquisa e desenvolvimento que, ao mesmo tempo em que se avança o conhecimento científico e tecnológico na área, propicie a formação, em grande escala, de recursos humanos altamente qualificados.

Dentro deste programa, destacam-se três ramificações: o Kyatera, um projeto cooperativo que visa ao estabelecimento de uma rede de fibras ópticas destinada à pesquisa, desenvolvimento e demonstração de tecnologias para aplicações da Internet Avançada; o Aprendizado Eletrônico, projeto que visa o desenvolvimento de ferramentas de suporte e apoio ao ensino e aprendizagem com interações presenciais e a distância, síncronas e assíncronas; e a Incubadora Virtual, um espaço para a criação cooperativa de conteúdos digitais. Cada projeto abriga outros subprojetos, alinhados com seus objetivos.

Dentro do projeto Kyatera, encontra-se o projeto ViNCES - (Virtual Network Center of Ecosystem Services) - coordenado pelo Laboratório de Automação Agrícola da Escola Politécnica da Universidade de São Paulo.

De acordo com Saraiva et al-b (2003), o projeto "ViNCES é um consórcio de laboratórios de pesquisa com foco em serviços ambientais, tais como fotossíntese e polinização. Seu objetivo é promover um melhor entendimento sobre os serviços ambientais, sua importância, magnitude e impacto, a partir de diferentes pontos de vista - científico, econômico e social - os quais poderão conduzir a uma utilização sustentável dos recursos naturais envolvidos". 
Os componentes deste consórcio são o Laboratório de Automação Agrícola LAA da Escola Politécnica da Universidade de São Paulo - EPUSP, o Laboratório de Abelhas do Instituto de Biociências (BEELAB, 2005) da Universidade de São Paulo - IBUSP e a Seção de Fisiologia e Bioquímica de Plantas do Instituto de Botânica (IB, 2005) da Secretaria de Estado do Meio Ambiente.

Entre outros trabalhos já realizados no âmbito do ViNCES, destacam-se o estudo de mudanças climáticas na fisiologia vegetal, através da criação de um sistema de controle da concentração de dióxido de carbono em uma câmara de topo aberto (ROMANO, 2006). Em outro estudo, Pereira (2006) desenvolveu um sistema de controle distribuído para casas de vegetação (estufas), permitindo o monitoramento e o controle remoto de variáveis ambientais tais como temperatura, umidade e luminosidade. As estruturas e equipamentos utilizados nestes trabalhos dão suporte para criação de weblabs que envolvam estes assuntos.

\subsubsection{Laboratório de Abelhas}

Outros trabalhos realizados no ViNCES dizem respeito a estudos de polinização e o uso de abelhas "sem ferrão" como agentes polinizadores. As abelhas estudadas pertencem à tribo Meliponini e são popularmente conhecidas como "sem ferrão" por ter seu ferrão atrofiado. Elas desempenham importante papel no serviço ambiental de polinização de plantas, agindo em fragmentos de florestas e culturas agrícolas, além de programas de desenvolvimento sustentável. Segundo Pereira (2005), “... as mesmas são responsáveis, dependendo do bioma, pela polinização de 80 a 90\% das plantas nativas no Brasil”. Até agora, 192 espécies de Meliponini foram descritas (SILVEIRA et al., 2002).

Entre as informações sobre estas abelhas disponíveis no projeto ViNCES estão aquelas provenientes do Webbee (seção 2.3), com dados sobre abelhas e plantas relacionadas. Especificamente para o ViNCES, foram incluídas fotos em alta resolução (2560 × 1920 pixels) e vídeos (640 x 480 pixels) com o objetivo de oferecer características morfológicas mais detalhadas das diferentes espécies e também para mostrar o comportamento das abelhas dentro das colméias.

Além dos dados citados acima, também foi construída uma infra-estrutura para a aquisição de dados sobre o comportamento destes insetos. Uma colméia da 
espécie Melipona quadrifasciata anthidioides foi adaptada para a realização de experimentos. Estão disponíveis dados obtidos por uma estação meteorológica localizada próxima à colméia, a fim de fornecer informações sobre as condições ambientais do entorno. Também estão disponíveis uma câmera de vídeo e um microfone, voltados para o interior da colméia. Ainda podem ser utilizados um contador para registrar a entrada e a saída de abelhas da colméia e um outro equipamento para permitir a leitura das condições de temperatura e umidade no interior, com estes dois últimos instrumentos ligados via rede de controle LON (Local Operating Network - Rede de Operação Local ) (ECHELON, 2006). A Figura 3.1 mostra um diagrama esquemático desta montagem. Fotos da montagem real são mostradas na Figura 3.2.

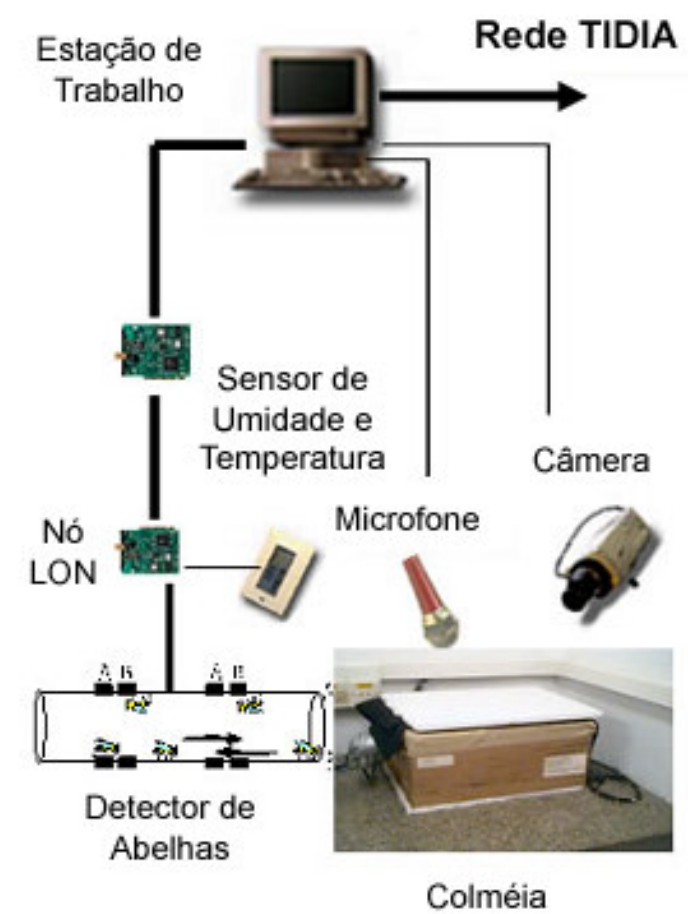

Figura 3.1 Diagrama representativo dos equipamentos utilizados no laboratório de abelhas. Extraído de (GIANNINI et al.-a, 2006).

Com esta configuração, podem ser feitos estudos para relacionar as condições ambientais com o comportamento das abelhas no interior do ninho (GIANNINI et al.-a, 2006). O som produzido nestas condições parece desempenhar um importante papel na comunicação destas abelhas, uma vez que ele é usado para codificar informação sobre a distância (MICHENER, 1974) apud (GIANNINI et al.-a, 2006) e altura dos recursos florais (NIEH, 2004) apud (GIANNINI et al.-a, 2006). 

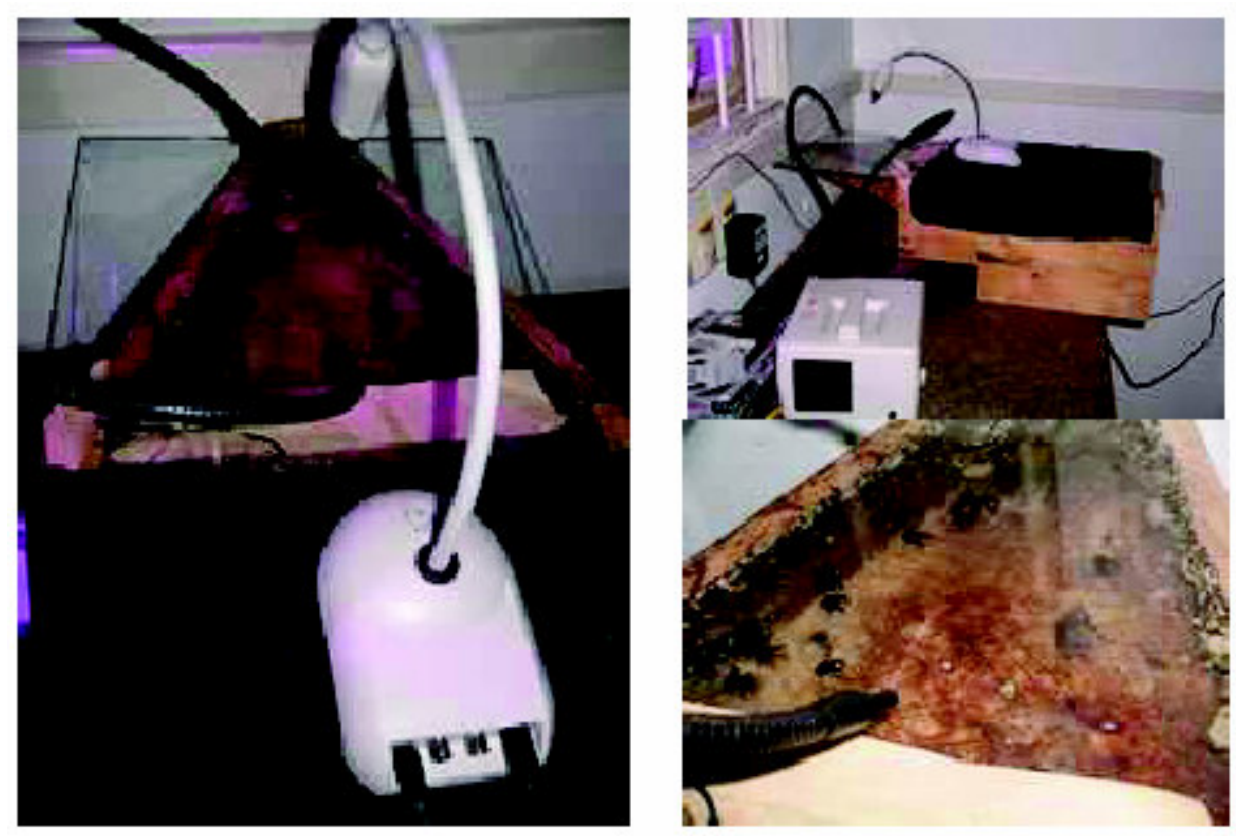

Figura 3.2. Montagem da câmera de vídeo e do microfone no laboratório de abelhas do projeto ViNCES. Extraído de (Giannini et al-b, 2006).

\subsection{Arquiteturas para weblabs}

Neste estudo levantaram-se modelos de arquiteturas que foram utilizadas anteriormente em outros projetos de weblabs.

Um primeiro modelo é aquele no qual a máquina do usuário conecta-se diretamente à máquina responsável pelo weblab. Um computador (ou conjunto de computadores) é ligado aos instrumentos, o qual executa uma aplicação que disponibiliza uma interface para manipulação dos instrumentos. Neste caso, geralmente um plug-in - programa que adiciona alguma funcionalidade específica a uma aplicação - deve ser instalado na máquina do usuário, a fim de permitir que ela possa enviar comandos diretamente ao servidor no laboratório real. Este modelo de arquitetura, com algumas variações, é empregado em vários projetos de weblabs (NEDIC; MACHOTKA; NAFALSKI, 2003; KHAMIS et al., 2003; KIKUCHI et al. 2004). A plataforma LabVIEW (MORIARTY et al., 2003) da empresa norte-americana National Instruments, é frequentemente utilizada nestes casos. No projeto Kyatera, uma alternativa obtida foi o desenvolvimento de uma interface Java para fazer a comunicação direta com o LabVIEW (OKAJIMA et al., 2006), o que evita a instalação 
de novos plug-ins, uma vez que a maior parte dos programas navegadores para a web (por exemplo Microsoft Internet Explorer e Mozilla Firefox) já têm hoje uma máquina virtual Java disponível. O controle direto dos instrumentos em geral é feito utilizando-se uma interface GPIB (General Purpose Interface Bus - Barramento de Interface para Propósito Geral), correspondente ao padrão IEEE 488 (TECHSOFT, 2005)

Um weblab está diretamente relacionado a um laboratório físico. Para diferentes laboratórios reais, diferentes weblabs podem ser criados. Em uma arquitetura que ligue a máquina do usuário diretamente à máquina responsável pelo laboratório, considerando que um mesmo usuário utilize diferentes weblabs, seu cadastro de usuário deverá estar presente em cada um dos weblabs, a fim de permitir seu uso em todo o sistema.

Um portal web é uma maneira de integrar sites web que sejam diferentes, porém relacionados. Quando existem vários weblabs em uma mesma área de conhecimento, um portal pode ser criado para permitir a integração destes laboratórios, oferecendo uma maneira uniforme e centralizada de acesso, permitindo a utilização destas estruturas de maneira mais eficiente.

Num ambiente que manipula vários weblabs, pode-se considerar elementos intermediários na arquitetura para fazer a mediação entre as máquinas que controlam o experimento de um laboratório e a máquina de usuário, um desses elementos é o portal (HARDISON et al., 2005; YAN et al., 2006; LANDI, LICCARDO, POLESE, 2006). Nestas arquiteturas são utilizados web services para fazer a comunicação entre o portal e as máquinas que controlam os laboratórios. $\mathrm{Na}$ arquitetura denominada iLab (HARDISON et al., 2005) do MIT (Massachusetts Institute of Technology - Instituto de Tecnologia de Massachusetts), web services também são utilizados para fazer a comunicação entre o portal e a máquina do usuário. Porém, como colocado por Yan et al. (2006), a utilização de web services para a comunicação no lado do usuário exige programas clientes mais complexos, não permitindo que o usuário utilize um simples programa navegador para acessar um weblab.

O uso de uma arquitetura distribuída permite atender melhor a demandas de escalabilidade, além de permitir a integração entre diferentes weblabs. Além disso, facilita também tarefas administrativas de controle de acesso e de gerenciamento de 
usuários. Esta abordagem é aplicada também no projeto ViNCES, além da utilização de um padrão aberto de metadados para representar os dados de experimentos manipulados. 


\section{Arquitetura Geral do Sistema}

\subsection{Visão geral}

A arquitetura apresentada neste capítulo foi especificada com o objetivo de atender as características específicas do Laboratório de Abelhas, as quais foram descritas no Capítulo 3. Porém para que essa arquitetura possa ser utilizada também como referência para outros laboratórios de serviços de ecossistemas, procurou-se abstrair durante a definição de seus componentes e serviços, funcionalidades gerais que possam também ser aplicadas a outros weblabs.

Assim para iniciar uma discussão sobre esses requisitos, são relacionadas a seguir as necessidades básicas desta arquitetura:

- acesso centralizado aos weblabs do projeto ViNCES;

- realização de experimentos a partir dos weblabs de maneira remota;

- recuperação de dados de experimentos previamente realizados;

- facilidade de análise de dados obtidos no experimento;

- acesso a banco de dados existentes (legados) com dados cadastrais, descrevendo o objeto do experimento (por exemplo: espécies de abelhas).

Além desses requisitos, foram também levantados requisitos não funcionais, necessários para um ambiente multiusuário e distribuído, citados a seguir:

- facilidade para a incorporação de novos weblabs ao sistema;

- controle de acesso aos weblabs e experimentos;

- registro de operações realizadas para fins de auditoria.

Como perfil dos usuários do sistema (stakeholders), considerou-se pesquisadores, estudantes, usuários não autenticados (anônimos) e administradores do sistema e outras aplicações (programas).

O modo básico de operação do sistema consiste no procedimento do usuário acessar o portal para escolher um weblab e realizar um experimento. Durante essa interação, diversos componentes dessa arquitetura estarão envolvidos, tais como: Portal, Provedor de WebLab, Provedor de Banco de Dados, dentre outros. A Figura 
4.1 representa os componentes de software da arquitetura, descritos nos próximos itens deste capítulo.

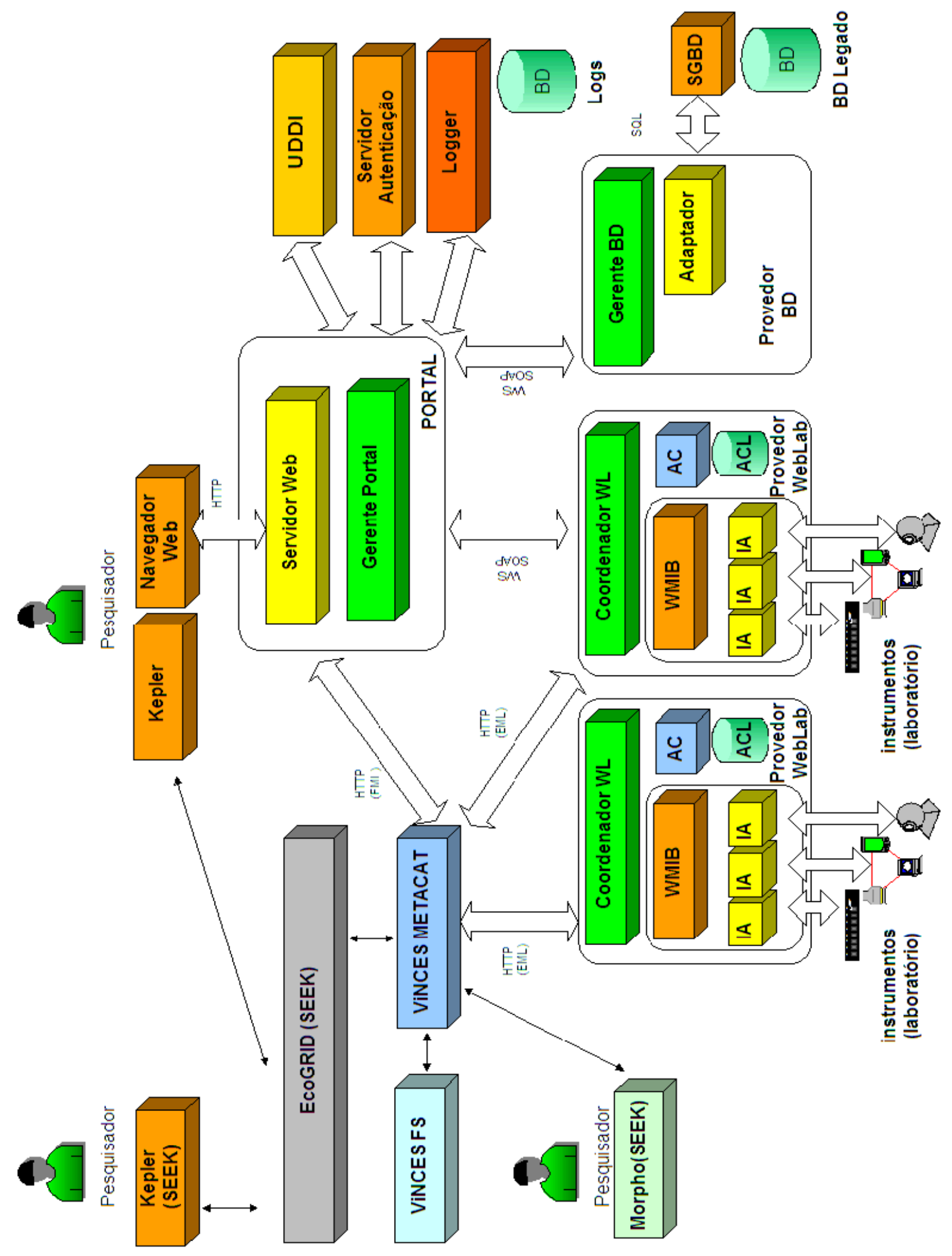

Figura 4.1. Arquitetura proposta para os WebLabs do projeto ViNCES. 


\subsection{Componente Portal}

O componente Portal (ver Figura 4.2) fornece aos usuários com perfil de pesquisadores o acesso ao sistema. Ele é composto por dois subcomponentes, citados a seguir:

- Servidor Web;

- Gerente Portal.

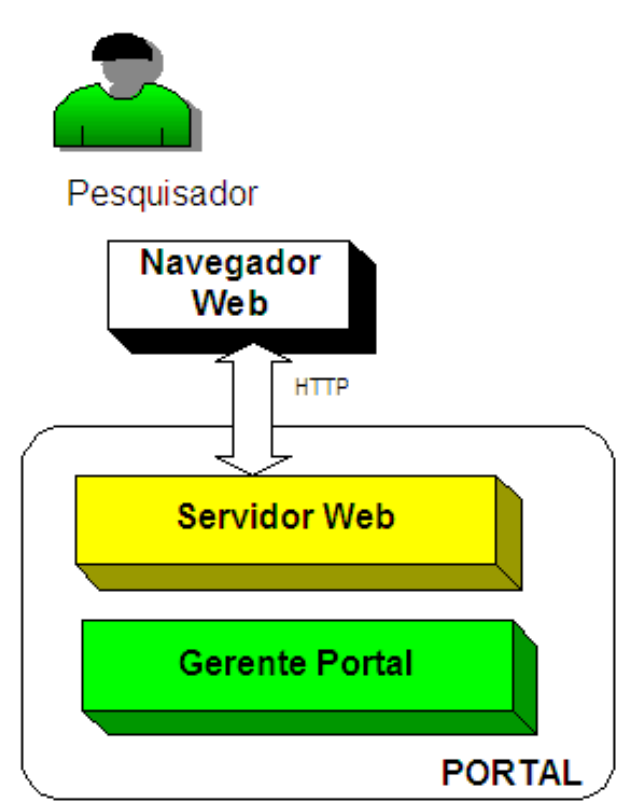

Figura 4.2 - Componente portal

O Servidor Web, juntamente com o programa Navegador Web (browser) do usuário, é responsável por fornecer a interface por meio da qual o sistema é utilizado, gerando páginas dinamicamente programadas a partir de uma linguagem de script. A comunicação entre o Servidor Web e o Navegador ocorre através do protocolo HTTP (HyperText Transfer Protocol - Protocolo de Transferência de Hipertexto). Caso seja necessária confidencialidade em alguma etapa específica da utilização - entrada de senha de acesso, por exemplo - a comunicação pode ocorrer por HTTPS (HyperText Transfer Protocol over Secure socket layer - Protocolo de Transferência de Hipertexto sobre camada de conexão Segura), conforme descrito em (FIELDING, 1999). 
O segundo sub-componente, Gerente Portal, faz a integração com os componentes Provedor WebLab e Provedor de Banco de Dados. As consultas ao registro UDDI e as autenticações também são feitas por este componente.

A seguir são citados dois serviços do componente Gerente do Portal, que permitem entender suas funcionalidades. Outros serviços envolvem 0 agendamento/configuração de experimentos e a recuperação de dados de experimentos já realizados, e são abordados durante o estudo de caso para o laboratório de abelhas.

\section{a) GetAuthentication}

O serviço GetAuthentication é responsável pela autenticação do usuário do sistema.

Este serviço exige uma consulta de credenciais no servidor de autenticação, a partir dos parâmetros:

- identificação do usuário - tais como login ou DN (Distinguished Name Nome Único);

- credenciais do usuário (senha).

Em caso positivo de autenticação, informações que o identificam são colocadas em um cookie seguro (LIU et al. , 2005), o qual é armazenado na máquina do usuário do sistema. Nos acessos subseqüentes do pesquisador, estas informações são automaticamente enviadas ao Portal, permitindo assim o devido tratamento pelo sistema.

Os usuários são previamente cadastrados, com um perfil associado a cada um deles, pelo administrador do sistema.

A seguir é apresentado um exemplo de dados trocados entre o Navegador e o Portal, durante a execução do serviço GetAuthentication:

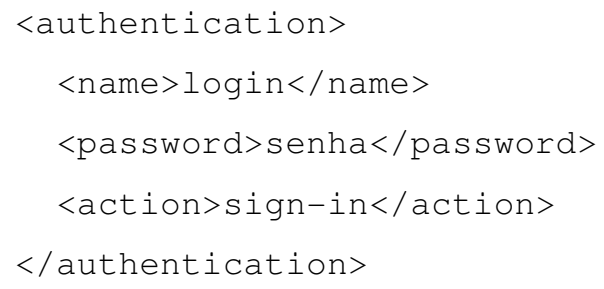


b) GetLabsList

O serviço GetLabsList lista os weblabs disponíveis para realização dos experimentos.

Este serviço exige uma consulta ao UDDI para recuperação dos weblabs disponíveis no sistema, descrevendo seus serviços que podem ser utilizados.

\subsection{Componente Provedor WebLab}

O componente Provedor WebLab faz a interface entre os instrumentos dos laboratórios físicos e o restante do sistema. Ele é composto pelos subcomponentes Coordenador WL (Weblab), WMIB (Weblab Management Information Base - Base de Informações de Gerenciamento do Weblab) e IA (Instrument Adapter - Adaptador de Instrumento), conforme a Figura 4.3.

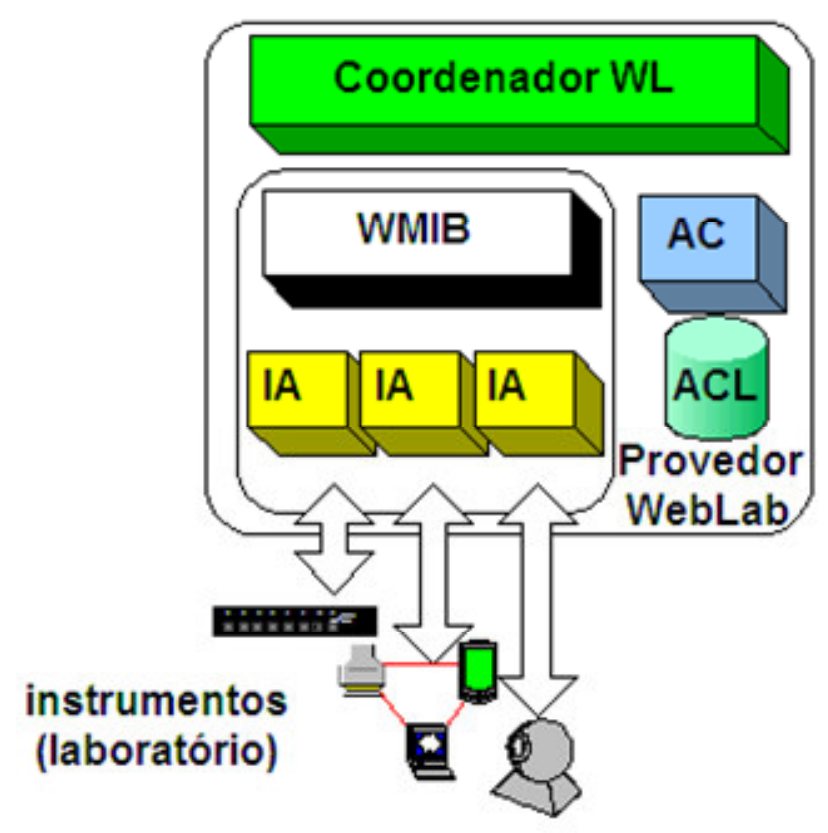

Figura 4.3. Componente Provedor WebLab.

$\mathrm{Na}$ definição deste componente, levou-se em consideração o conceito de experimento de laboratório de acordo com o definido por Festinger, 1971 apud Moreira, 2000:

Um experimento de laboratório pode ser definido como aquele no qual o investigador cria uma situação com as condições exatas que ele deseja ter 
e na qual ele controla algumas variáveis e manipula outras. Ele então (o investigador) é capaz de observar e medir o efeito da manipulação das variáveis independentes sobre as variáveis dependentes numa situação na qual a operação de outros fatores relevantes é mantida em um mínimo.

Desta maneira, para a realização de experimentos nos weblabs o pesquisador deve, conforme colocado na definição acima:

- ter condições de criar uma situação com as condições que ele deseja;

- ser capaz de observar e medir as variáveis dependentes.

Para a primeira premissa, na realização de experimentos nos WebLabs do projeto ViNCES, o pesquisador deve poder atuar ou inicializar os instrumentos existentes no WebLab; para a segunda, o pesquisador deve ser capaz de ler os valores das variáveis dos instrumentos sempre que necessitar.

Ao final de um experimento, o pesquisador obtém um conjunto de dados que caracterizam o experimento realizado. Consideraram-se os seguintes dados para caracterizar um experimento (ver Figura 4.4):

- dados cadastrais - metadados do experimento, dizem respeito ao autor, descrição, objetivos, métodos, data/hora, tipos de acesso permitido ao conjunto de dados, etc.;

- dados dos atores - espécie(s) e/ou espécime(s) envolvidos no experimento;

- dados ambientais - condições a que os atores estiveram submetidos durante a realização do experimento, por exemplo, temperatura interna, temperatura externa, umidade, pressão;

- dados de comportamento - áudio/vídeo do laboratório, número de entradas e saídas de abelhas em uma colméia, etc. 


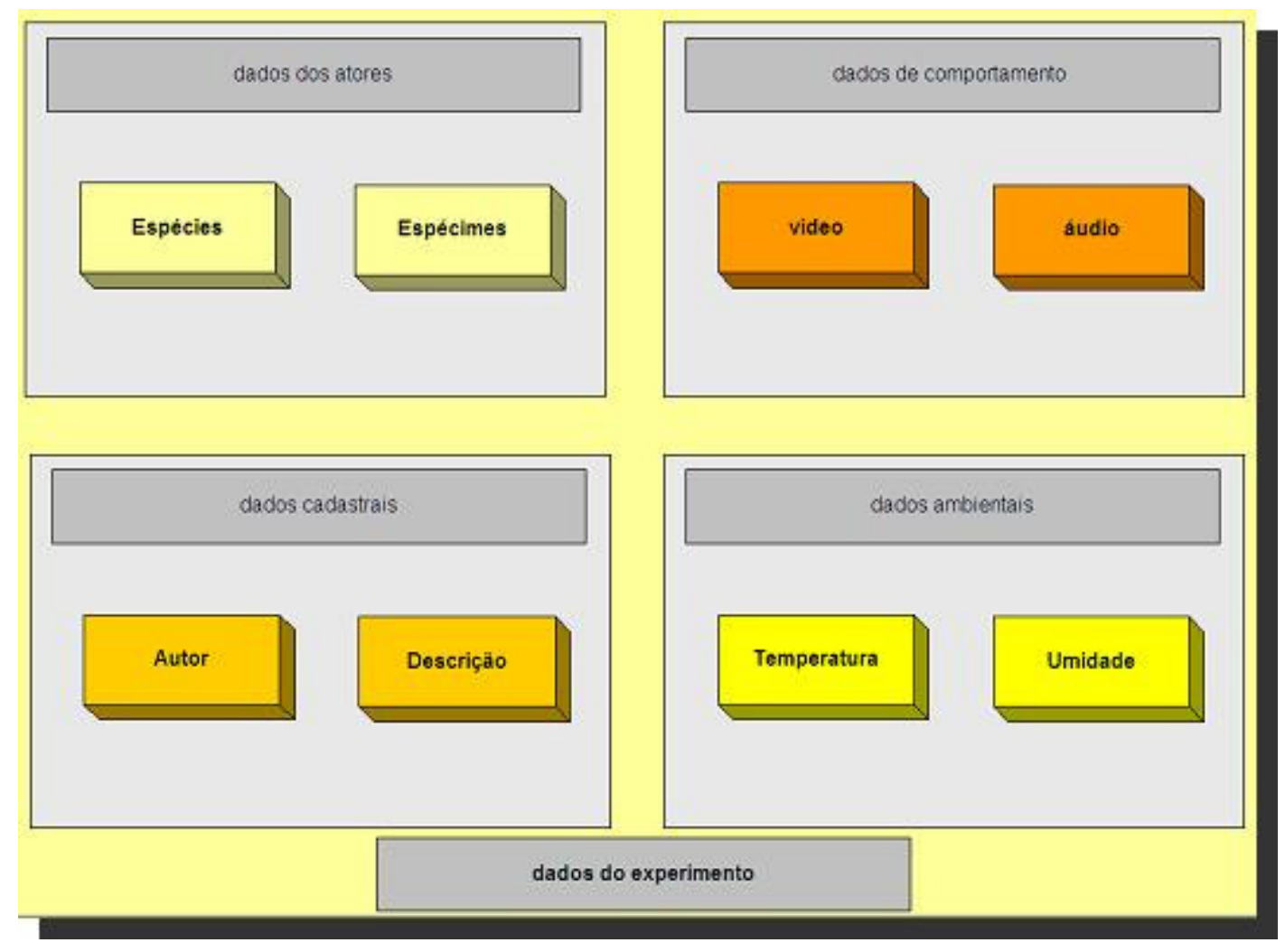

Figura 4.4. Exemplo de dados obtidos ao final do experimento em um um weblab do projeto ViNCES

Nesta arquitetura somente um experimento pode ser realizado em um Weblab de cada vez, o que está de acordo com o uso normal de laboratórios reais.

\subsubsection{Subcomponentes WMIB e IA}

Este subcomponentes têm por objetivo fazer o gerenciamento dos instrumentos existentes nos WebLabs, permitindo a configuração dos parâmetros de um instrumento e a leitura das suas variáveis associadas, de acordo com as premissas citadas acima.

O WMIB (Weblab Management Information Base - Base de Informações de Gerenciamento do Weblab) empresta, de maneira simplificada, o conceito do elemento MIB (Management Information Base) utilizada em redes gerenciados segundo a arquitetura SNMP (ver Capítulo 2). 
Na WMIB, os instrumentos são representados como registros - ou objetos, conforme a implementação escolhida. Para instrumentos passivos o valor de uma determinada medida é obtido lendo-se o campo/atributo correspondente à variável. Para atuação no instrumento, altera-se o campo/atributo pertinente. A Tabela 4.1 mostra uma representação de exemplo de WMIB.

Tabela 4.1. Exemplo de extrato de um WMIB (Weblab MIB).

\begin{tabular}{|l|c|c|c|c|c|c|}
\hline Instrumento & Termômetro1 & \multicolumn{3}{|c|}{ Estação Meteorológica } & Contador1 & Contador2 \\
\hline Variável & $\begin{array}{c}\text { Temperatura } \\
\text { (interna) }\end{array}$ & $\begin{array}{c}\text { Temperatura } \\
\text { Externa }\end{array}$ & Umidade & Luminosidade & $\begin{array}{c}\text { Entrada de } \\
\text { abelhas }\end{array}$ & $\begin{array}{c}\text { Saída de } \\
\text { abelhas }\end{array}$ \\
\hline Unidade & ${ }^{\circ} \mathrm{C}$ & ${ }^{\circ} \mathrm{C}$ & $\%$ & LUX & Indivíduos & indivíduos \\
\hline Valor atual & 25 & 22 & 70 & 800 & 3 & 2 \\
\hline
\end{tabular}

O componente IA (Instrument Adapter - Adaptador de Instrumento) faz o papel de traduzir da representação da variável na WMIB para a atuação/monitoração real. Uma mudança de um campo na WMIB dispara um chamado de um serviço na IA para mapear aquela modificação no instrumento físico. Analogamente, para obtenção de uma medida de um instrumento, um outro serviço é utilizado na IA a fim de obter o valor desejado, o qual é depois repassado à WMIB para atualização. $A$ Figura 4.5 exemplifica o processo de interação WMIB/IA/Instrumento.

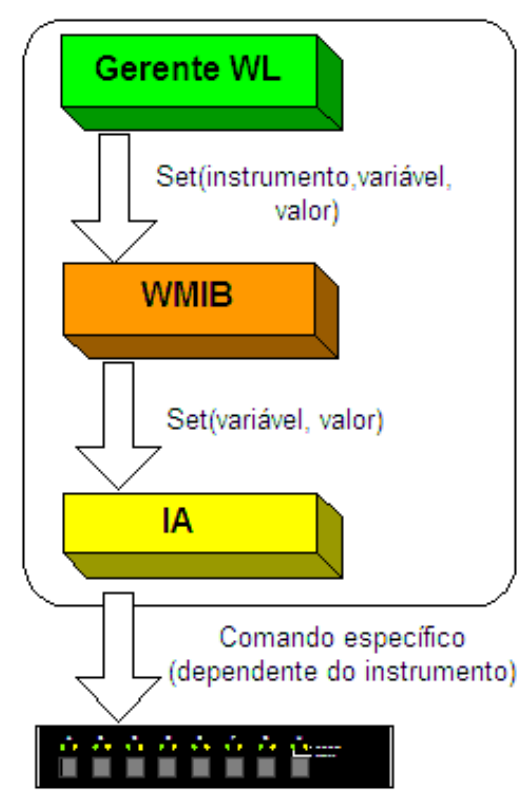

Figura 4.5. Exemplo de interação para atuação em um instrumento. 
O componente IA é dependente do instrumento físico a ser utilizado ou, alternativamente, da arquitetura de rede de instrumentação utilizada. Há um IA diferente para cada conjunto de padrão de instrumentos/rede de instrumentação presente no laboratório físico. No entanto, todos devem fornecer à WMIB os mesmos serviços de leitura e escrita de valores nos instrumentos.

Normalmente os instrumentos do laboratório fornecem medidas que podem ser representadas por um valor escalar, acompanhado de uma respectiva unidade. Por exemplo, um medidor de pressão fornece um valor de $720 \mathrm{mmHg}$ em uma determinada leitura. Nos laboratórios do projeto ViNCES porém, há outros tipos de equipamentos que não seguem este padrão. Instrumentos que retornam dados multimídia estão entre eles.

Desta maneira, uma câmera de vídeo ou um microfone, por exemplo, requerem que o elemento IA envolvido permita ligar ou desligar a gravação de dados do equipamento e também recuperar um apontador dos dados registrados. Um exemplo de apontador poderia ser uma URL (Uniform Resource Locator Localizador Uniforme de Recursos), o qual aponta para um arquivo com os dados de áudio ou vídeo registrados durante o experimento.

Um outro caso a ser considerado é o de funções especiais dos instrumentos, as quais podem ser mapeadas por meio de indicadores (flags) na WMIB. Como ilustração, uma função de inicialização de um instrumento poderia ser mapeada como uma variável reset na WMIB. Se esta variável for escrita com o valor "1", por exemplo, o IA faria a inicialização do instrumento correspondente.

\subsubsection{Controle de acesso}

O controle de acesso é feito utilizando o modelo RBAC (Role Based Access Control- Controle de Acesso Baseado em Papéis) conforme (SANDHU et al., 1996). São previstos inicialmente para este sistema os papéis de administrador, pesquisador e estudante. Um papel implícito é o de usuário não autenticado, ao qual corresponderia o papel de anônimo. Eventualmente, pode haver uma gradação dentro do papel de pesquisador, fato que obrigaria à criação de várias papéis de acordo com os privilégios desejados: pesquisador nível 1, pesquisador nível 2, etc. 
Devido ao pequeno número de papéis esperados, à baixa hierarquia eventualmente existente entre eles e à falta de restrições que exigissem modelos mais complexos de controle de acesso, o modelo adotado neste caso é o RBAC (SANDHU et al, 1996). Neste modelo os elementos básicos são "usuários (U), papéis $(R)$, permissões (P) e sessões (S)", como segue (SANDHU et al. 1996):

- usuários : usuários do sistema ViNCES;

- papel ou perfil : uma classificação atribuída a um usuário que representa a autoridade e a responsabilidade atribuída ao usuário associado a este papel;

- permissão : o modo como os objetos podem ser acessados;

- sessão : período de tempo no qual o sistema está sendo empregado de modo contínuo por um determinado usuário.

Um usuário pode ter mais de um papel, e um papel pode ter mais de uma permissão associada. Um usuário é quem efetivamente exerce a permissão, sendo que os papéis são somente um modo para facilitar a administração do controle de acesso.

Uma definição formal da relação entre usuários, papéis, permissões e sessões é apresentada por Sandhu et al. (1996) :

PA: Permission Assignment (Atribuição de Permissões), uma relação permissão-papel muitos-para-muitos

$P A \subseteq P \times R$

UA : User Assignment (Atribuição de Usuários), uma relação usuário-papel muitos-para-muitos

$\mathrm{UA} \subseteq U \times R$

User: $\mathrm{S} \rightarrow \mathrm{U}$, uma função mapeando cada sessão si a um único usuário (constante por toda a duração da sessão)

No Provedor Weblab, o mapeamento PA listado acima é feita com o auxílio da ACL (Access Control List - Lista de Controle de Acessos). O mapeamento UA é feito no serviço de Autenticação (Servidor de Autenticação juntamente com a base de dados), externo ao componente Provedor Weblab 
Credenciais recebidas pelo provedor Weblab são comparadas com a $A C L$ para efeitos de autorização. Em caso positivo, o acesso à operação desejada é liberado.

\subsubsection{Componente Coordenador WL}

O Coordenador WL (Figura 4.3) é responsável por receber as requisições de realização de experimentos vindos do portal e também por acessar o componente WMIB para pedidos de monitoração e atuação no instrumento. Este componente também controla o registro de dados durante um experimento e faz o acesso à base de dados ViNCES Metacat (Figura 4.1) para registrar dados de experimentos já realizados.

A seguir são citados alguns serviços deste componente:

a) GetLabResources

O serviço GetLabResources é responsável por fornecer as capacidades de um laboratório. Este serviço lista os instrumentos disponíveis em um laboratório e seus recursos, no que diz respeito tanto às variáveis que podem ser monitoradas quanto aos parâmetros que podem ser passados para eventual atuação em um instrumento.

b) SetInstrument

O serviço SetInstrument permite uma atuação em um instrumento do laboratório. Dado um instrumento, um parâmetro deste instrumento e o valor desejado, o valor é escrito na WMIB.

c) Readlnstrument

O serviço Readlnstrument permite a monitoração de uma medida feita por um instrumento do laboratório. Este serviço faz a leitura de uma variável de um instrumento e retorna o valor lido.

d) SetExperiment 
O serviço SetExperiment configura um laboratório para a realização de um experimento. Após a verificação de credenciais, define as configurações nas quais os instrumentos do laboratório serão inicializadas e define as variáveis que serão monitoradas. Define também os metadados (autor, métodos, data/hora, objetivos, etc.) do experimento. Se não for fornecido o parâmetro de entrada que define a identificação para o experimento, cria-se um novo experimento e o serviço retorna uma identificação única associada a ele para eventuais acessos posteriores.

e) ExperimentStart

O serviço ExperimentStart inicia o registro de dados para o experimento cuja identificação foi passada como parâmetro de entrada. Muda o status do Weblab para "em uso" a fim de não permitir atuações outras durante a realização do experimento.

\section{f) ExperimentEnd}

O serviço ExperimentEnd finaliza o registro de dados para o experimento cuja identificação foi fornecida como parâmetro de entrada, libera o laboratório para novos experimentos e grava o conjunto de dados do experimento no componente Metacat do sistema (os dados são gravados utilizando o esquema EML). Do conjunto de dados obtidos (Figura 4.4), os dados cadastrais e de atores (espécimes envolvidos) correspondem aos elementos do pacote EML, enquanto os outros dados - de comportamento e ambientais - são registrados como tabelas descritas em EML. Como citado, arquivos multimídia podem ser representados por apontadores para estes arquivos.

\subsection{Componente Provedor de Dados}

O componente Provedor de Banco de Dados permite que bancos de dados legados sejam acessados pelo sistema. Como este trabalho está focado em Weblabs de Serviços Ambientais, prevê-se que podem ser consultados bancos de dados já existentes com registros sobre espécies eventualmente envolvidas nos 
experimentos realizados. Como retorno desta operação temos a recuperação das informações relativas à espécie em questão. Por exemplo, integrando o banco de dados do projeto Webbee ao sistema, pode-se ter um apontador para a ficha de espécies nos dados a serem salvos no EML.

Os subcomponentes presentes são (Figura 4.6) :

- Gerente BD;

- Adaptador BD.

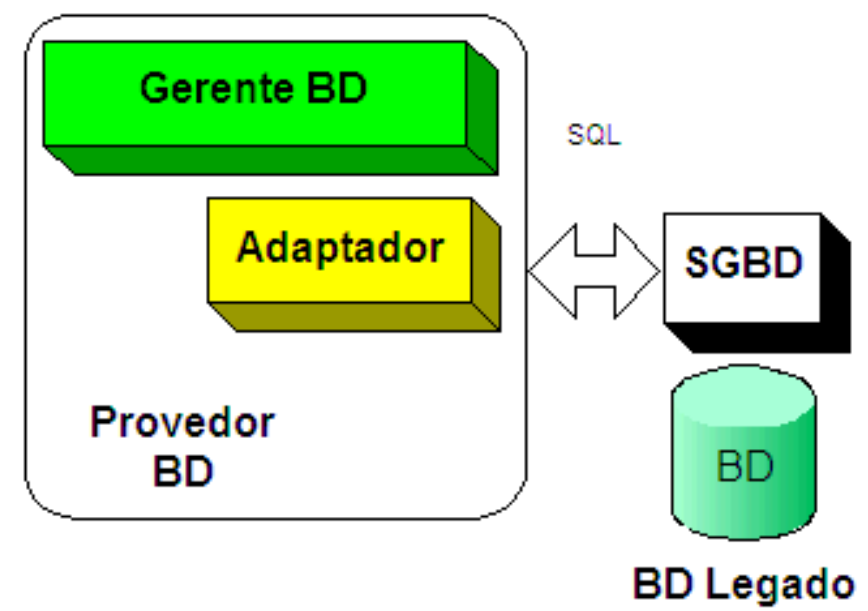

Figura 4.6. Componente Provedor de Banco de Dados.

O primeiro é responsável por receber os pedidos de consulta à base legada, normalmente a partir do nome da espécie envolvida. O segundo é o que faz a conversão do pedido recebido para uma linguagem de pesquisa - comumente em SQL (Structured Query Language - Linguagem de Consulta Estruturada) (COSTA, 2007), à semelhança da função desempenhada pelo subcomponente Instrument Adapter. As instruções em SQL são passadas para o SGBD (Sistema Gerenciador de Banco de Dados), o qual executa a consulta. Não são previstas atualizações nos dados armazenados em um banco de dados legado, apenas consultas.

Em uma implementação, o protocolo DiGIR pode ser considerado para resolver o problema de consulta no banco de dados legado. 
A seguir são citados os principais serviços deste componente.

a) Search

O serviço Search permite uma pesquisa por um nome de espécie, retornando uma lista de referências para espécies encontradas.

b) GetSpeciePointer

O serviço GetSpeciePointer tem como parâmetro de entrada uma referência a uma espécie, retornando as informações detalhadas sobre a espécie, como por exemplo os dados taxonômicos.

\subsection{Outros componentes}

Neste item são citados os elementos de software dessa arquitetura que fornecem serviços básicos para gerenciamento e análise de metadados de experimentos, controle de acesso e registro de serviços (Web Services).

a) Integração com as ferramentas da arquitetura SEEK.

Estes elementos (Figura 4.7) fornecem a possibilidade de integração do sistema com a rede do projeto SEEK, com grandes vantagens no tocante especialmente à análise de dados.

Conforme discutido, o conjunto de dados obtidos a partir de um experimento é armazenado utilizando o esquema de metadados EML. Para armazenamento deste registro em EML e posterior recuperação, é utilizado um Servidor Metacat, representado nesta arquitetura pelo componente ViNCES Metacat.

Os dados (tabelas relativas a dados ambientais coletados) são armazenados através do componente ViNCES FS (File Server - Servidor de Arquivos), em conjunto com o Servidor Metacat, como mostrado na Seção 2.2.2.

Para posterior pesquisa e recuperação de dados de experimentos pode ser utilizado o componente Portal em consulta direta com o Metacat. A autorização requerida para acesso ao registro EML fica registrada no módulo eml-access do documento armazenado, e é definida no momento de configuração do experimento. 
O acesso aos experimentos realizados pode também ocorrer através de um cliente Morpho (Seção 2.2.1), configurado para acesso direto pelo componente ViNCES Metacat.

A incorporação de uma base de dados Metacat nesta arquitetura permite a conexão ao Ecogrid, e a partir daí, o uso da ferramenta Kepler (seção 2.2.3). Com a utilização deste componente, os dados obtidos nos WebLabs podem ser analisados por qualquer pesquisador com as credenciais de autorização adequadas.

b) Registros de serviços através de UDDI.

O componente UDDI foi incluído para servir de repositório para os documentos WSDL (Seção 2.5), os quais descrevem os Web Services disponíveis no sistema.

c) Servidor de autenticação.

O componente servidor de autenticação é responsável pela validação das credenciais de identidade apresentadas pelo usuário. Adicionalmente, na base de dados de autenticação é também armazenado o papel atribuído ao usuário.

\subsection{Outras considerações}

Não foram totalmente considerados nesta arquitetura instrumentos para o auxílio do usuário com perfil Administrador para execução de suas tarefas. Deste modo, o registro de novos WebLabs deverá ser feito diretamente pelo Administrador.

Outro ponto não contemplado foi o uso de comandos "relativos" para a atuação em instrumentos. Pelos serviços propostos, não é possível o envio de uma configuração como "-45 graus" para uma câmera com base giratória, somente um valor absoluto, como "75 graus", por exemplo. No entanto, esta limitação pode ser facilmente contornada quando se combina a leitura do estado atual com o valor relativo desejado. O resultado é o novo valor absoluto que deve ser enviado para o instrumento. 


\section{Estudo de caso - Laboratório de abelhas}

Neste capítulo são descritos cenários de utilização do sistema baseado na arquitetura apresentada no Capítulo 4, com o objetivo de mostrar como ocorre a articulação entre os componentes da arquitetura. Para estudo de caso são considerados dois cenários: o primeiro diz respeito à criação de um experimento no weblab correspondente ao Laboratório de Abelhas (Seção 3.2.1) e o segundo a posterior recuperação de dados obtidos naquele experimento.

\subsection{Criação de experimento}

O experimento a ser realizado é o de estudo da variação da influência da temperatura interna da colônia na atividade externa de abelhas Melipona quadrifasciata, a fim de pesquisar as condições ambientais externas e internas que determinam modificações na atividade externa. Para realização deste experimento é feita a modificação da temperatura interna de uma colônia, com posterior registro de variáveis de entrada e saída de abelhas da colméia, além de dados de temperatura e umidade internas e externas.

Para iniciar a utilização do sistema, o usuário (pesquisador) faz o login no portal, informando o nome usuário e sua senha. As credenciais apresentadas são verificadas pelo subcomponente Gerente Portal, junto ao Servidor de Autenticação (Figura 4.1). Em caso positivo de autenticação, o componente Gerente Portal faz uma pesquisa junto ao UDDI para recuperação dos WebLabs disponíveis. Em seguida, é gerada dinamicamente uma tela onde são apresentadas as opções de acesso aos WebLabs existentes no Portal ViNCES (Figura 5.1). Outras abas da interface permitem acessar os dados de experimentos previamente realizados pelo usuário ou uma pesquisa para recuperação de dados de experimentos em geral.

O pesquisador escolhe em seguida o WebLab de abelhas. Uma pesquisa no ViNCES Metacat é efetuada para apresentar experimentos feitos naquele WebLab que já tenham dados registrados. Adicionalmente, o usuário pode escolher a opção de criar um novo experimento (Figura 5.2). 


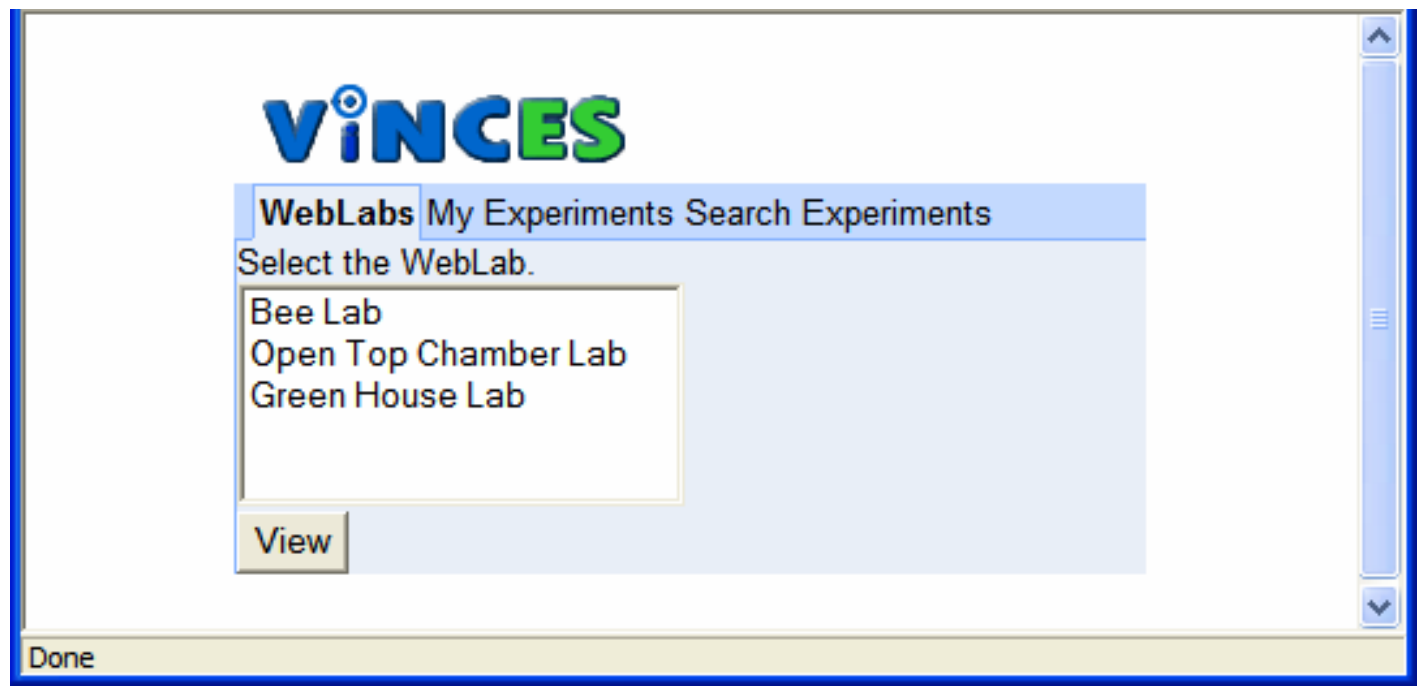

Figura 5.1. Apresentação dos WebLabs do Portal ViNCES.

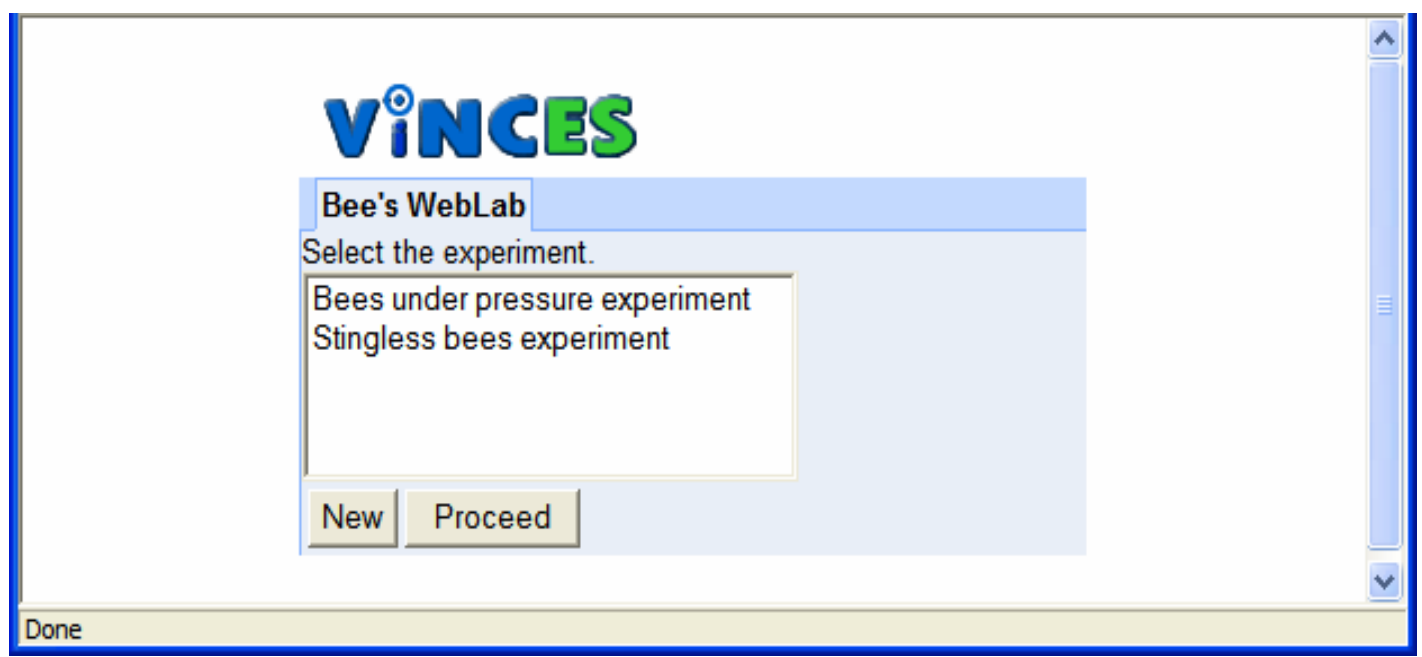

Figura 5.2. Tela para criação de novo experimento.

Ao se escolher a opção de criar um novo experimento, é inicialmente apresentada uma tela com dados gerais do experimento, correspondentes aos campos do pacote EML que será gerado ao final do processo. São disponibilizados dados do experimento referentes ao título, autor, contato, resumo e palavras-chave do estudo, dentre outros (Figura 5.3). 


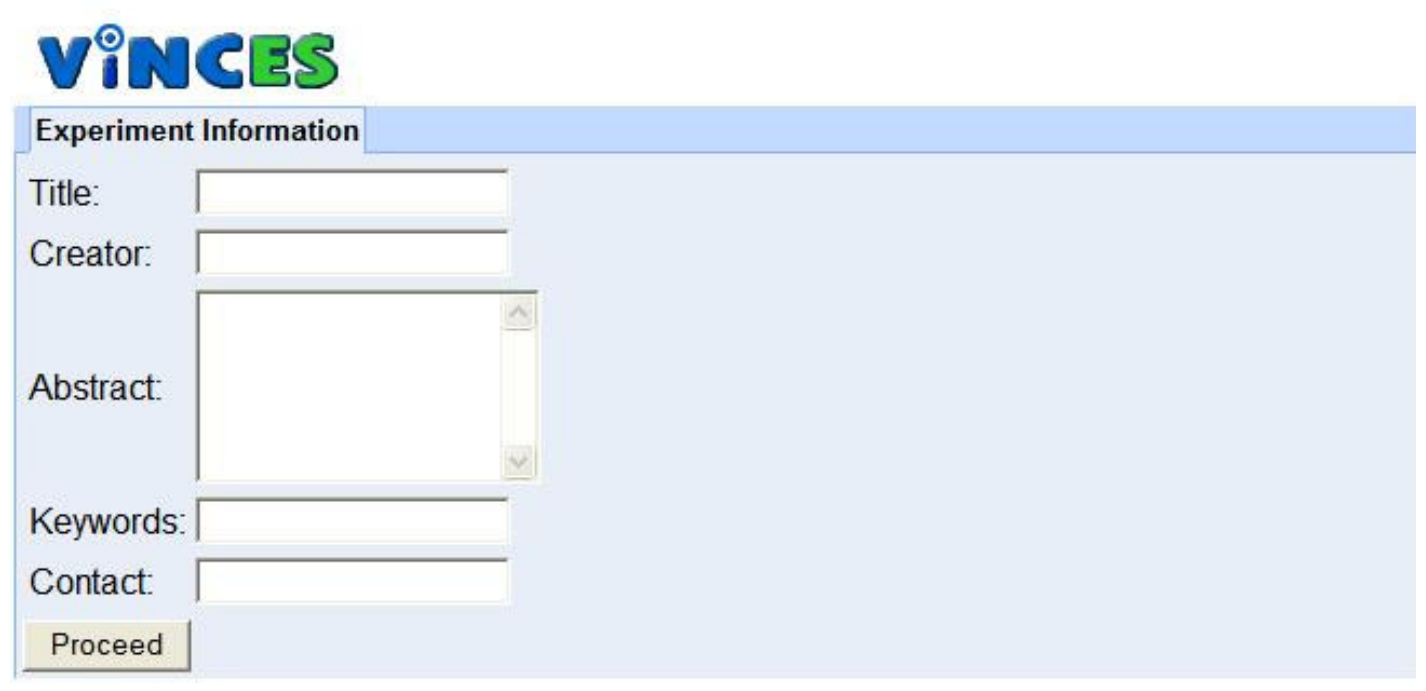

Figura 5.3. Dados gerais do Experimento.

Após preencher estes dados, o componente Provedor WebLab do Laboratório de Abelhas é acessado via web services para obtenção da lista de sensores e instrumentos existentes, com as respectivas variáveis a serem monitoradas e parâmetros a serem pré-configurados, de acordo com o conceito de experimento apresentado na Seção 4.3.

O pesquisador escolhe a configuração desejada para o experimento, selecionando $o$ instrumento e as variáveis correspondentes. Por exemplo, para registro das condições ambientais internas, o instrumento NOSE1 é selecionado, e em seguida o pesquisador escolhe as variáveis temperatura e umidade. A cada seleção feita, uma caixa na interface com as variáveis a serem monitoradas é automaticamente preenchida (Figura 5.4). A cada variável escolhida neste passo corresponde a uma tabela no pacote EML gerado ao final do experimento. As análises feitas por meio do componente Kepler ou através de outros componentes de análise, podem utilizar os dados existentes nessas tabelas.

Para a configuração de pré-condições do experimento, escolhe-se 0 instrumento correspondente e a condição desejada. Para o experimento em questão, a temperatura interna da colméia deve ser modificada. Para isto, o pesquisador deve selecionar $O$ instrumento aquecedor e em seguida, escolher a temperatura desejada (Figura 5.5). A importância da correta associação de um 
usuário a um perfil é mostrada neste ponto. Se o usuário não for um pesquisador com ciência dos limites do objeto de estudo, a colocação de uma temperatura muito alta, pode prejudicar ou mesmo inviabilizar a colônia.

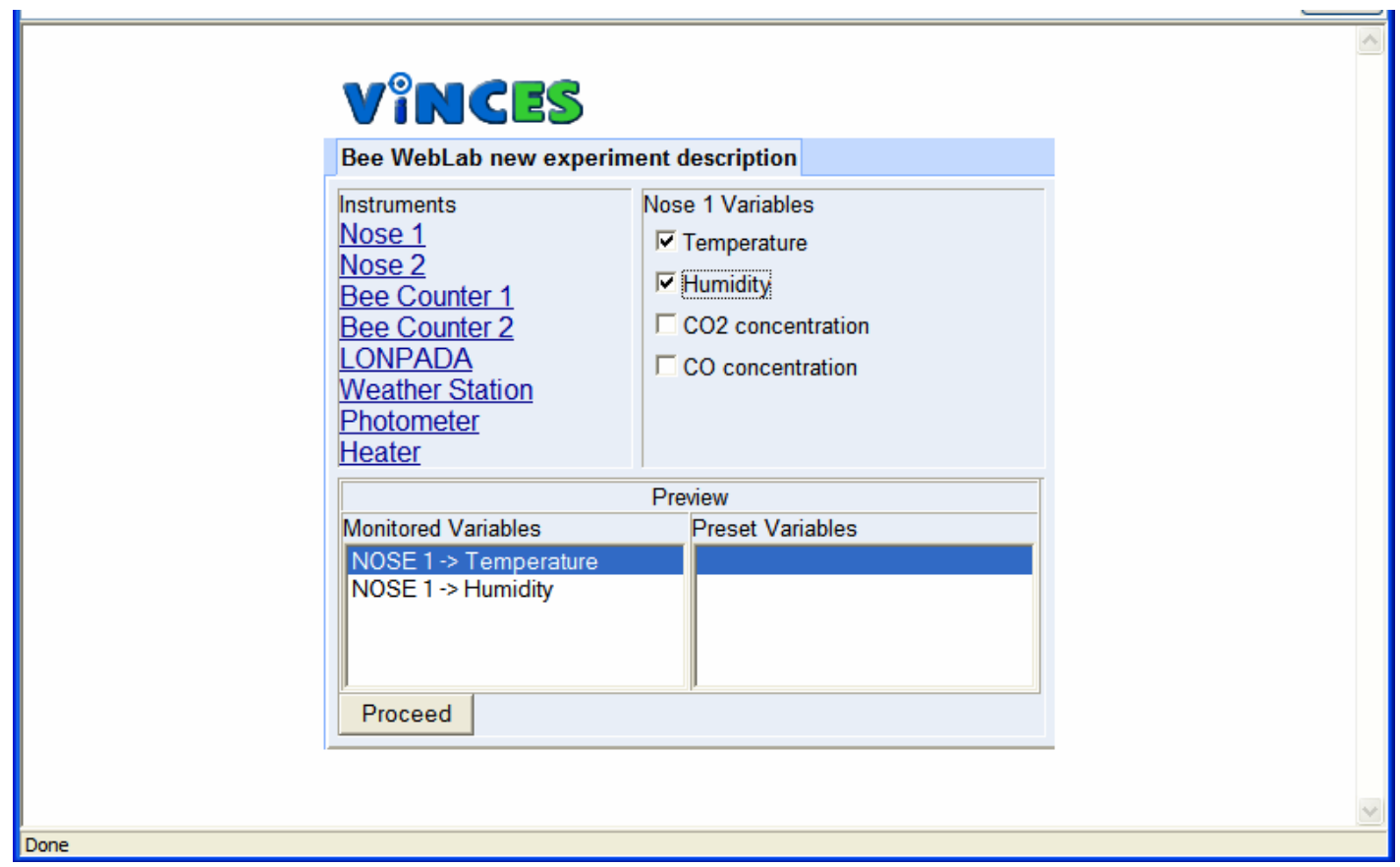

Figura 5.4. Seleção de variáveis monitoradas.
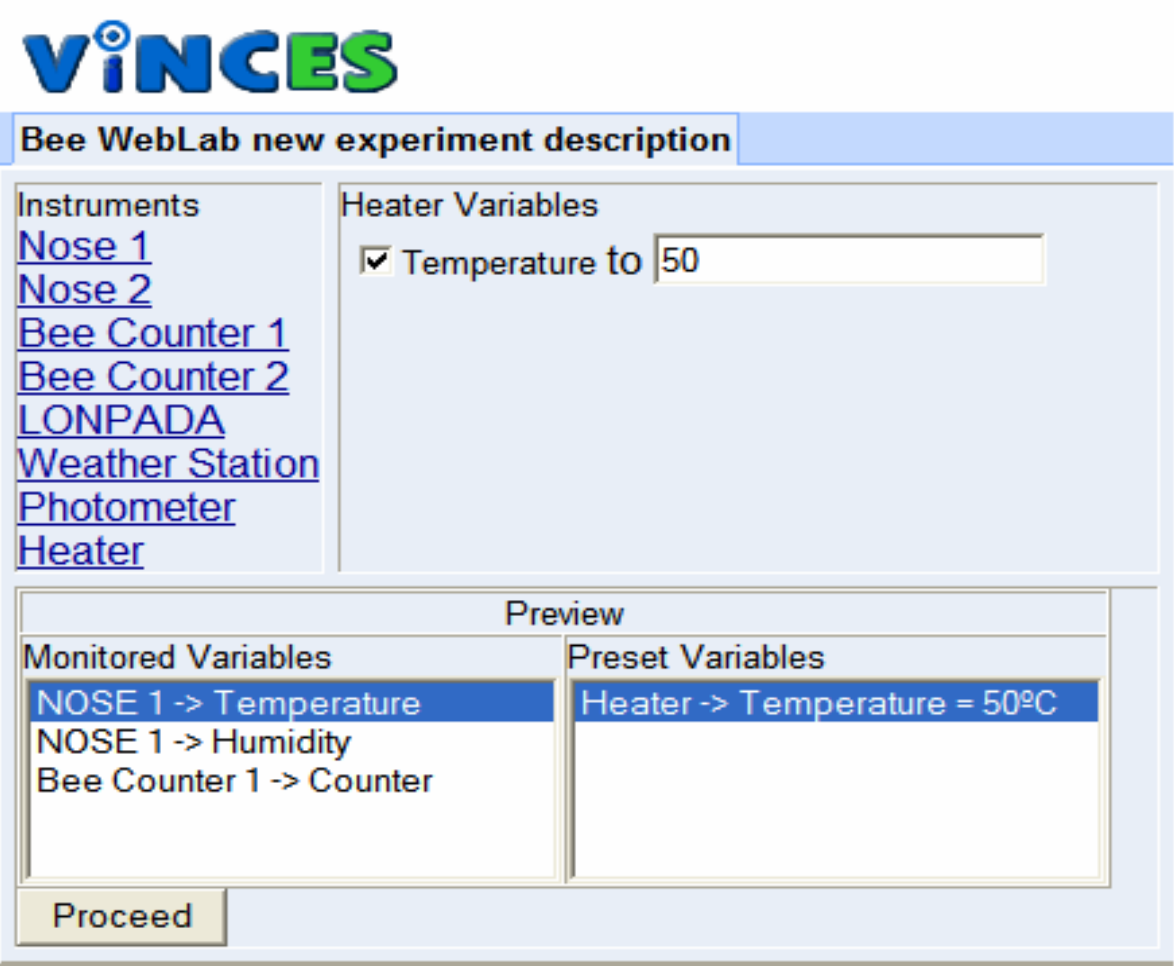

Figura 5.5. Configuração da temperatura interna da colônia. 
Por fim, uma vez que todos as variáveis monitoradas e pré-condições estejam preenchidas, o pesquisador deve informar quais são a data/hora de início e final desejadas para a duração do experimento (Figura 5.6). Estes dados são passados para o provedor do WebLab de abelhas que verifica a disponibilidade. Caso o WebLab esteja vago entre os horários desejados, uma mensagem de confirmação do experimento é apresentada; em caso contrário outros horários são requisitados.

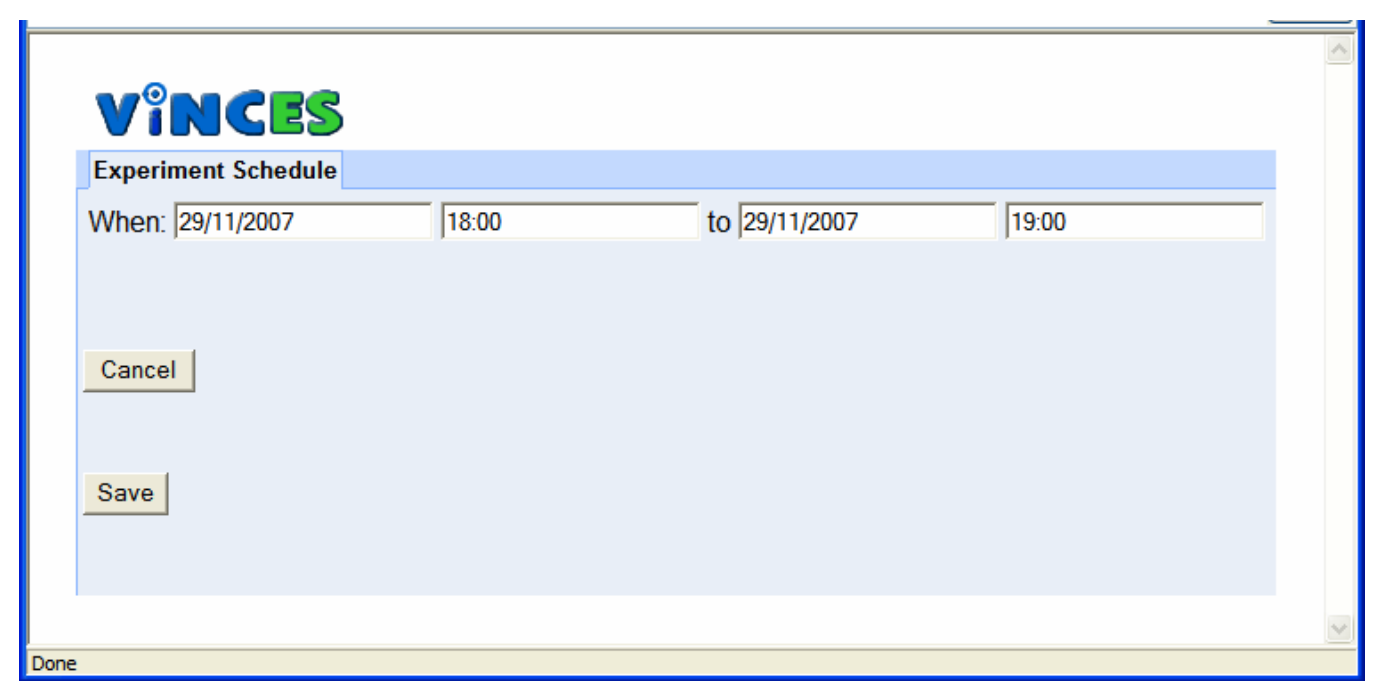

Figura 5.6. Agendamento do experimento no Weblab de abelhas.

Os dados gerais (autor, descrição, resumo), variáveis monitoradas, précondições requeridas e os horários de execução do experimento são armazenados no provedor WebLab do laboratório de abelhas, a partir de onde o experimento será registrado. Para efeitos de auditoria, o portal também faz um registro do pedido por meio do componente Logger (Figura 4.1).

\subsection{Recuperação de dados de experimento}

Para recuperação de dados de experimento já executado, o usuário previamente autenticado tem a opção de selecionar um de seus próprios experimentos já registrados (Figura 5.7) ou fazer uma pesquisa genérica na base de dados ViNCES Metacat.(Figura 5.8).

No primeiro caso, a recuperação automática dos experimentos é feita a partir de parâmetros de identidade de usuário armazenados no cookie na máquina do pesquisador. O subcomponente Gerente Portal executa a consulta ao ViNCES Metacat, obtém uma lista de experimentos já realizados pelo pesquisador e 
apresenta esta informação. No segundo caso, é apresentado um formulário para pesquisa, cujos campos são utilizados para pesquisa no ViNCES Metacat.

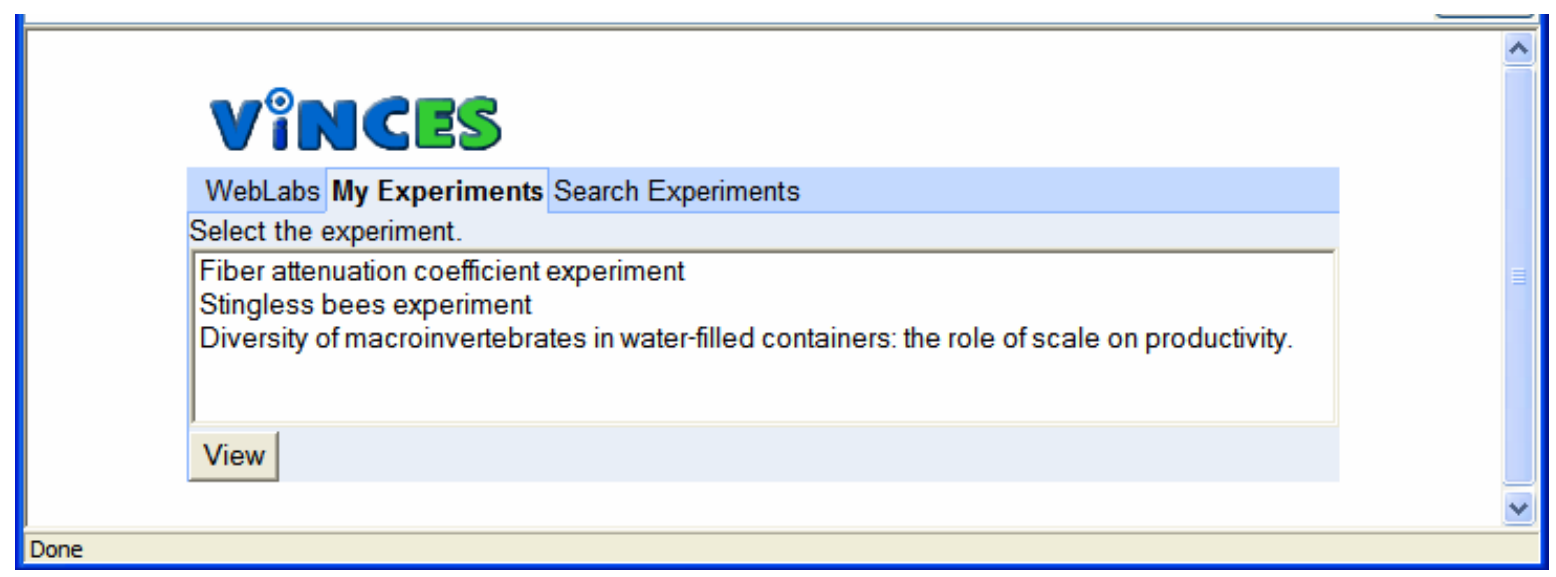

Figura 5.7. Lista de experimentos do pesquisador.

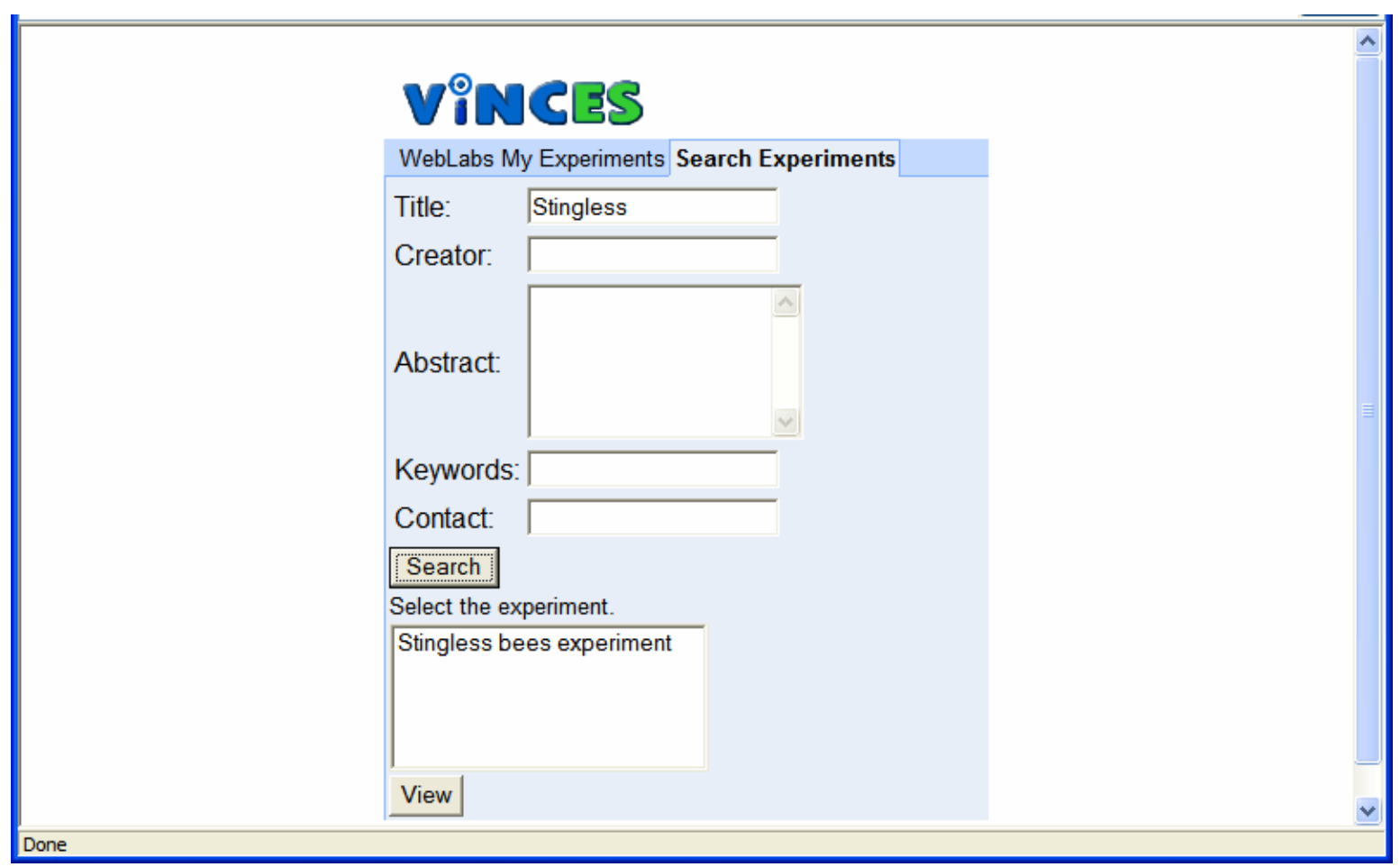

Figura 5.8. Pesquisa genérica de experimentos disponíveis.

Ao final da pesquisa, o experimento selecionado pode ser visualizado em HTML por meio de uma conversão dos dados realizada pelo subcomponente Gerente Portal, que estavam originalmente em formato EML. O resultado é disponibilizado pelo servidor web do Portal, tornando-se acessível por qualquer aplicativo navegador da Internet. (Figura 5.9). 


\section{viness \\ Experiment View}

\begin{tabular}{|r|l|}
\hline Study Number: & 1001 \\
\hline Project Title: & Stingless bee in hot conditions \\
\hline Investigator(s): & $\begin{array}{l}\text { Marcelo Succi Tel. 999.999.9999 } \\
\text { Leonardo Bessa Tel. 999.999.9998 }\end{array}$ \\
\hline Affiliated Institution(s): & Escola Politécnica - USP \\
\hline Keywords: & $\begin{array}{l}\text { Lorem ipsum dolor sit amet, consectetuer adipiscing elit. Quisque eros velit, tincidunt ut, vestibulum id, scelerisque } \\
\text { blandit, tortor. Nam pellentesque tellus quis ligula. In egestas, purus in ultrices dapibus, sapien nulla feugiat nisi, } \\
\text { quis lobortis dolor pede id est. Nunc malesuada, leo nec hendrerit bibendum, dui ante dictum massa, vitae auctor } \\
\text { dolor justo vitae odio. Pellentesque quis eros hendrerit lacus eleifend dictum. Donec lorem ante, ultrices id, viverra } \\
\text { vel, dapibus eget, odio. Donec sit amet purus ac erat auctor convallis. In ligula. Aliquam risus lacus, tristique nec, } \\
\text { ultricies at, bibendum non, orci. Nulla tincidunt. Nulla facilisi. Pellentesque habitant morbi tristique senectus et } \\
\text { netus et malesuada fames ac turpis egestas. Phasellus porta iaculis odio. Nullam tristique tortor eu arcu. Cras } \\
\text { quis pede id arcu euismod tempor. Nulla facilisi. Nullam enim. Sed leo tellus, accumsan at, mollis ut, volutpat at, } \\
\text { nisi. Sed nisi. } \\
\text { Contact: }\end{array}$ \\
$\begin{array}{l}\text { Proin sit amet lorem. Cras nonummy. Cras vitae velit id nisl accumsan viverra. Praesent at neque a nisl accumsan } \\
\text { pulvinar. Morbi ut tellus. Fusce eros est, porta sit amet, rhoncus aliquet, commodo quis, nisl. Proin suscipit. } \\
\text { Mauris venenatis vestibulum sapien. Pellentesque rutrum, velit at auctor pretium, massa odio hendrerit tortor, eget } \\
\text { vestibulum diam ante rutrum ante. Aliquam vel quam id augue ultricies cursus. }\end{array}$ \\
\hline stingless bees, heat. \\
\hline nobody@ nowhere.com \\
\hline
\end{tabular}

Figura 5.9. Dados de um experimento recuperado. 


\section{Conclusão}

Este capítulo contém as considerações finais sobre este trabalho. São apresentadas as conclusões obtidas para a arquitetura projetada além de sugestões para trabalhos futuros.

\subsection{Contribuições e conclusões}

O uso do paradigma de orientação a serviços no projeto da arquitetura sugerida foi interessante por permitir uma abordagem modular para a resolução do problema. A arquitetura obtida ficou genérica de forma que outros weblabs além daqueles de serviços ambientais podem se valer desta arquitetura como base para o planejamento de soluções específicas.

Pelo uso da ferramenta portal, o usuário do sistema tem acesso centralizado aos diferentes weblabs. Eventuais tarefas administrativas em relação às contas de usuário - criação, modificação, remoção - são facilitadas, pois não é necessário que haja uma base de usuários a ser mantida em cada weblab.

O estudo de elementos da arquitetura do SEEK para o compartilhamento de dados de weblabs ambientais, revelou-se uma solução adequada para o problema proposto. Ao analisar os padrões ali adotados, foi possível verificar que a linguagem EML aplica-se adequadamente para a documentação de experimentos realizados nos weblabs, em especial quando comparado com outros padrões de metadados de biodiversidade, já que EML prevê estruturas para a representação de dados observados. Esta representação permite análises mais automatizadas destes dados. As restrições ficam por conta de experimentos que envolvam elementos multimídia. Embora haja soluções de compromisso para representar vídeos ou dados, EML ainda é mais adequada para representar dados que possam ser expressos em forma tabular.

A escolha do componente Metacat para armazenagem dos dados de experimentos possibilita que o componente ViNCES Metacat possa integrar-se ao Ecogrid do projeto SEEK, permitindo que pesquisadores tanto do ViNCES como de outros projetos, façam suas análises acessando dados de experimentos realizados 
nos weblabs, através de ferramentas avançadas de análise como a ferramenta Kepler.

Outro resultado relevante foi a adoção de SNMP-MIB para o tratamento das interfaces com os instrumentos dos weblabs. Este uso permitiu separar o complexo problema de monitorar/atuar nos instrumentos dos weblabs em duas partes: ler e atuar em uma variável representativa do instrumento, representada dentro da MIB, e depois fazer o mapeamento entre esta variável e o correspondente físico no sensor/atuador, função desempenhada pelo componente IA na arquitetura. Com esta concepção, diferentes padrões de instrumentação podem ser utilizados no weblab, dado que o IA correspondente tenha sido desenvolvido, sem sobrecarregar o provedor weblab.

\subsection{Trabalhos futuros}

A arquitetura sugerida é uma primeira aproximação para a integração de weblabs de serviços ambientais. Trabalhos podem ser sugeridos em relação ao acoplamento com os instrumentos físicos, operação dos weblabs, ou ainda da apresentação dos weblabs para o usuário.

Desta maneira, uma primeira sugestão de trabalho em relação à arquitetura é o desenvolvimento dos subcomponentes IAs, em especial para o padrão LON, utilizado em vários instrumentos nos laboratórios do projeto ViNCES. A partir deste desenvolvimento, os instrumentos podem ser integrados aos weblabs facilmente, permitindo a realização de experimentos mais complexos.

Uma segunda sugestão diz respeito à implementação de serviços que possibilitem uma atuação dinâmica dos experimentos, por exemplo, incrementando a temperatura de uma colméia de abelhas na taxa de $1^{\circ} \mathrm{C} / \mathrm{h}$ durante um determinado período. No estado atual, isto não é possível. Variações dinâmicas das condições do experimento também permitiriam a execução de experimentos mais ricos.

A interface do usuário com os instrumentos apresentada neste trabalho, ainda que funcional, foi simples. Sensores e atuadores são apresentados como caixa de texto em um navegador, o que tira o "senso de realidade", como descrito por (DERVIS, BULANCAK; OZCAN, 2003). 
O programa Labview, citado no Capítulo 3, fornece uma ótima interface para os instrumentos, dando o "senso de realidade" desejado. No entanto, não pode ser considerado em uma solução que se planeja aberta, que permita a integração de vários weblabs. Assim, uma terceira sugestão de trabalho é o estudo de modos de construção de uma GUI (Graphic User Interface - Interface Gráfica de Usuário) para os instrumentos nesta arquitetura. Um possível caminho é o uso da linguagem XML para fornecer a indicação do lay-out do painel de instrumentos, como mostrado por (YAN et al. 2006). Os dados representados em XML podem ser convertidos em elementos gráficos, por exemplo, utilizando o ActionScript do software Flash MX (REINHARDT; LOTT, 2002). 


\section{Lista de referências}

$A B C D$ An Introduction to the ABCD Schema v2.0 Disponível em http://ww3.bgbm.org/abcddocs/Abcd Acesso em : 17 de dezembro de 2006

ALTINTAS, I. et al. Kepler: an extensible system for design and execution of scientific workflows In : Proceedings of 16th International Conference on Scientific and Statistical Database Management, Jun 2004, p.423-424, 2004

ARPAIA,P. et al. A measurement laboratory on geographic network for remote test experiments In: IEEE Transactions on Instrumentation and Measurement, v.49, n.5, p.992-997, Out 2000

BARRY AND ASSOCIATES. Service-oriented architecture (SOA) definition . Disponível em : < http://www.service-architecture.com/web-services/articles/serviceoriented_architecture_soa_definition.html>. Acesso em : 04 de maio de 2005 .

BEELAB - Laboratório de Abelhas. Disponível em: <http://eco.ib.usp.br/beelab>. Acesso em: 09 de Agosto de 2005.

BERENDSOHN, W. Mapping between Darwin Core 2 (DwC) and ABCD 2.06

Disponível em http://www.bgbm.org/TDWG/CODATA/Schema/Mappings/DwC2.0.htm Acesso em 10 de setembro de 2006, Out 2005

BERNERS-LEE, T. Metadata Architecture . Disponível em : http://www.w3.org/ Designlssues/ Metadata.html. Acesso em : 20 de setembro de 2006, Jan. 1997

BioCASE Biological Collection Access Service for Europe. Disponível em http://www.biocase.org). 
CASE, J. et al. RFC $\mathbf{3 4 1 0}$ - Introduction and Applicability Statements for Internet Standard Management Framework. Disponível em : http://www.apps.ietf.org/rfc/ rfc3410.html. Acesso em: 15 de agosto de 2006, Dez 2002

CHIRICO M., SCAPOLLA A.M, BAGNASCO. A new and open model to share laboratories on the Internet In: IEEE Transactions on instrumentation and measurement 54, p.1111-1117, 2005.

COSTA, R.L.C. SQL Guia Prático, Brasport, 2007, 148 p.

COSTANZA, R. et al. The value of the world's ecosystem services and natural capital, Ecological Economics, v. 25, n. 1 , p.3-15, Abr 1998

DAILY, G.C. et al.Ecosystem services: benefits supplied to Human societies by natural ecosystems. Issues in Ecology,n.2,spring 1997, Ecological Society of America. Disponível em <http://esa.sdsc.edu/issues.htm>. Acesso em: 15 de maio de 2006.

DEL ALAMO,J.et al.The MIT Microelectronics WebLab: a Web-Enabled Remote Laboratory for Microelectronic Device Characterization, World Congress on Networked Learning in a Global Environment, 2002. Disponível em < http://wwwmtl.mit.edu/ alamo/pdf/2002/RC-88\%20delAlamo\%20NL\%202002.pdf> Acesso em : 07 de julho de 2006.

DENIZ,D.Z;BULANCAK,A.;OZCAN,G. A novel approach to remote laboratories Proceedings of 33 rd Frontiers in Education, p. T3-E8 - T3E-12, Nov 2003

DiGIR - The University of Kansas - Natural History Museum . Descrição do protocolo Disponível em : http://www.specifysoftware.org//nformatics/informaticsdigir/. Acesso em : 23 de setembro de 2006 
- Descrição do software, acesso a códigos-fonte Disponível em http://digir.sourceforge.net/ Acesso em : 11 de maio de 2006

ECHELON The LonWorks Platform: Technology Overview - Disponível em: http://www.echelon.com/developers/lonworks/default.htm. Acesso em : 05 de maio de 2006

ECOINFORMATICS COLLABORATORY Apresentação do laboratório de Ecoinformática da Universidade de Vermont (UVM) Disponível em : http://ecoinformatics.uvm.edu/ Acesso em : 20 de dez de 2006

ENDREI, M. et al., Patterns: Service-oriented Architecture and Web Services, IBM Redbook, 2004 Disponível em :http://www.redbooks.ibm.com. Acessado em : 04 de agosto de 2006.

FESTINGER, L. Laboratory Experiments. In: William M. Evan, ed. Organizational Experiments: Laboratory and Field Research. New York. Harper and Row Publishers., 1971

FIELDING, R. et al. RFC 2616 - Hypertext Transfer Protocol - HTTP/1.1, Jun 1999

GARCIA-ZUBIA, J.; DEL MORAL, A.;Suitability and Implementation of a WebLab in Engineering In: IEEE Conference on in Emerging Technologies and Factory Automation, 2005. ETFA 2005. v 2, Set. 2005 p.49-56.

GeoCASE Geosciences Collection Access Service- Descrição - Disponível em : http://projects.naturkundemuseum-berlin.de/synthesys_activity_d/ Acesso em : 20 de dezembro de 2006

GIANNINI, T.C. et al Webeelabs: weblabs of Brazilian bees. Proceedings of the 5th International Conference on Ecological Informatics ISEI5, 2006.

A Weblab for monitoring and characterization of stingless bee (Meliponini) Proceedings of III Workshop TIDIA, 2006 
HARDISON, J. et al. The Microelectronics Weblab 6.0 - an implementation using web services and the iLAB shared architecture, Proceedings of the International Conference on Engineering Education and Research 2005, Mar 2005

HIGGINS,D.; BERKLEY,C.; JONES,M.B.; Managing Heterogeneous Ecological Data Using Morpho, In: Proceedings. 14th International Conference on Scientific and Statistical Database Management, 2002, Jul 2002 p.69 - 76

HYLANDS,C. Overview of the Ptolemy Project. Disponível em : http://ptolemy.eecs. berkeley.edu/index.html Acesso em : 17 de novembro de 2006, Jul 2003

IB - Instituto de Botânica de São Paulo. Disponível em: http://www.ibot.sp.gov.br Acesso em: 09 de Agosto de 2005.

JONES,M.B. et al. Managing scientific metadata in IEEE Internet Computing, Volume 5, no. 5, Out 2001, p.59- 68

KEPLER - Kepler: An Extensible System for Scientific Workflows . Descrição do software Disponível em: http://kepler.ecoinformatics.org Acesso em : 17 de novembro de 2006

KIKUCHI et al. DVTS-based remote laboratory across the Pacific over the gigabit network In: IEEE Transactions on Education, v.47, n.1, p.26-32, Fev 2004

KLASKY, S.A.; LUDAESCHER, B.; PARASHAR, M.;The Center for Plasma Edge Simulation Workflow Requirements. Proceedings of 22nd International Conference on Data Engineering Workshops, p.73, Abr 2006

KNB PROJECT - Ecological Meta Data Language (EML) - Disponível em http://knb.ecoinformatics.org/software/eml. Acesso em 8 de setembro de 2005 
KHAMIS, A. et al, M.; Pattern-based architecture for building mobile robotics remote laboratories Proceedings of IEEE International Conference on Robotics and Automation, ICRA '03, v.3, p.3284-3289, Set 2003

KUROSE, J.F; ROSS, K.W - Redes de computadores e a Internet : uma abordagem top-down, 3.ed, São Paulo: Pearson Addison-Wesley, 2006,634 p.

LANDI, C.; LICCARDO, A.;POLESE,N Remote Laboratory Activities to Support Experimental Session for Undergraduate Measurements Courses In: Proceedings of The 23rd IEEE Instrumentation and Measurement Technology Conference, IMTC 2006. p.:851-856, Abr 2006

LANE, M.G; HESS, H.K. On-Line Ecological Data Validation: An Expansion Of A Minicomputer-based Key Entry System. In : Proceedings of the annual conference ACM 76, p.259-264, Out 1976

LIU, A.X et al. A Secure Cookie Protocol In: Proceedings of the 14th IEEE International Conference on Computer Communications and Networks (ICCCN-05), Out 2005

MICHENER, C. D. The social behaviour of the bees. A comparative study. Cambridge, Belknap Press, 404 p, 1974

MICHENER, W.K. ET AL Nongeospatial metadata for the ecological sciences. In: Ecological Applications 1997 n. 1 p.330-342

MORA, M. Presentácion de Plinian Core - Disponível em http://www.inbio.ac.cr/ taller_iabin/pdf/k/Metodolog\%EDa\%20para\%20el\%20desarrollo\%20de\%20las\%20herr amientas\%20de\%20la\%20red.pdf Acesso em : 20 de dezembro de 2006

MORIARTY et al. Graphical computing in the undergraduate laboratory: Teaching 
and interfacing with LabVIEW. In: American Journal of Physics v.71, n.10, p.10621074, Out 2003

MOREIRA, D.A. Natureza e Fontes do Conhecimento em Administração In: Administração On Line - Revista Eletrônica da FECAP Disponível em : http://www.fecap.br/adm_online/art11/daniel.htm, Acesso em 12 de setembro de 2006, Jan 2000

NEDIC,Z;MACHOTKA,J;NAFALSKI,A Remote laboratories versus virtual and real laboratories. Proceedings of 33 rd Frontiers in Education, p. T3-E1 - T3E-6, Nov 2003

NIEH, J. C. Recruitment communication in stingless bees (Hymenoptera, Apidae, Meliponini). Apidologie, v. 35, p. 159-182, 2004

PAPAZOGLOU M.P.; GEORGAKOPOULOS, D. Service-Oriented Computing In Communications of the ACM Vol. 46, No. 10, Out 2003

PARTNERSHIP FOR BIODIVERSITY INFORMATICS. SEEK -Science Environment for Ecological Knowledge, 2004 Disponível em : <http://seek.ecoinformatics.org/>. Acesso em 06 de novembro de 2005.

PEREIRA, F.M. Abelhas sem ferrão, a importância da preservação Disponível em: http://www.embrapa.br/noticias/artigos/folder.2005-02-02.1550581232/artigo.2005-1229.3499364899/mostra_artigo Acesso em : 22 de novembro de 2006, Dez 2005

PEREIRA,G.A. Sistema experimental de monitoramento e controle para casas de vegetação baseado em redes de controle distribuídos LonWorks, 2006, $125 f$. Dissertação(Mestrado) - Escola Politécnica, Universidade de São Paulo, São Paulo, 2006

REINHARDT, R.; LOTT, J. Macromedia Flash MX ActionScript Bible, Wiley, 2002 
ROMANO,R.A. Modelagem e controle de $\mathrm{CO}_{2}$ em Câmaras de Topo Aberto, utilizadas em estudios de fisiologia ambiental, 2006, 82f. Dissertação(Mestrado) Escola Politécnica, Universidade de São Paulo, São Paulo, 2006

SANDHU, R. et al. Role-Based Access Control Models IEEE Computer v.29 n.2, p.38-47, Fev 1996

SARAIVA et al. WebBee - a Web-based Information Network on Bees - Revista de Engenharia de Computação e Sistemas Digitais, n.1,v.1, p.77-86 , Nov 2003. Disponível em <http://www.pcs.poli.usp.br/revista/n1/r001a007.pdf>. Acesso em 03 maio de 2005 .

Virtual Networking Center of Ecosystem Services - ViNCES, Ago, 2003 Disponível em <http://www.kyatera.fapesp.br/portal/V.part/vinces/ document_view>. Acesso em 26 de abril de 2005.

SILVEIRA, F. A.; MELO, G. A. R. ; ALMEIDA, E. A. B. Abelhas brasileiras: sistemática e identificação. $1^{\underline{a}}$ Ed. MMA e Fund. Araucária, Belo Horizonte - MG. 253p., 2002

SOYSAL, O. Computer Integrated Experimentation in Electrical Engineering Education over Distance In: Proceedings of ASAEE 2000 Annual Conference, jun.2000.

STAL, M. Web Services: Beyond Component-Based Computing. In: Communications of ACM, v. 45 n.10, p.71-76, out, 2002.

STEPHENS, R.T Utilizing Metadata as a Knowledge Communication Tool In: Proceedings of International Professional Communication Conference(IPCC2004), p.55-60, 2004 
STUTOR, B. The definitions of Web Services. jan. 2003. Disponível em: http://searchwebservices.techtarget.com/originalContent/0,289142,sid26_gci874060,0 0.html Acesso em : 30 de abril de 2005.

TECHONLINE What is VirtuaLab? Disponível em : http://www.techonline.com/ product/virtualab/moreAboutVlab.jhtml. Acesso em 05 de novembro de 2006, 2005

TECHSOFT TBasic GPIB Tutorial Disponível em: ttp://www.techsoft.de/htbasic/ utgpibm.htm?tutgpib.htm. Acesso em : 12 de dezembro de 2006

TIDIA. Tecnologia da Informação no Desenvolvimento da Tecnologia Avançada. Apresentação do projeto TiDIA, coordenado pela Fapesp. Disponível em: $<$ http://www.tidia.fapesp.br/portal//.projetos/kyaTera>. Acesso em: 15 de maio de 2005.

VIEGLAIS, D. - The Darwin Core Disponível em http://speciesanalyst.net/docs/dwc. Acesso em: 11 de novembro de 2006, Ago 2003

W3C - WORLD WIDE WEB CONSORTIUM. Web Services Glossary .Disponível em http://www.w3.org/TR/2003/WD-ws-gloss-20030514 Acesso em : 04 de mai 2005

WIECZOREK,J - Purpose and design goals of the Darwin Core. Disponível em http://wiki.tdwg.org/twiki/bin/view/DarwinCore/DesignAndPurpose Acesso em : 11 de novembro de 2006, 2006

YAN, Y. et al. Putting labs online with Web services In : IT Professional, v. 8, n.2, p.27-34, Mar 2006 